\title{
Simulation Analysis of the Tensile Mechanical Properties of a Hydraulic Strain Clamp-Conductor System
}

\author{
Zhongfei Ye, ${ }^{1}$ Kai Pang $\mathbb{D}^{1},{ }^{1}$ Yuanxiang Du, ${ }^{2}$ Guifeng Zhao ${ }^{2,3}$, Shao Huang, \\ and Meng Zhang $\mathbb{D}^{2,3}$ \\ ${ }^{1}$ State Grid Henan Electric Power Corporation Electric Power Research Institute, \\ Key Laboratory of Power Transmission Line Galloping Prevention and Control Technology, Zhengzhou 450052, China \\ ${ }^{2}$ School of Civil Engineering, Zhengzhou University, Zhengzhou 450001, China \\ ${ }^{3}$ Department of Civil and Environmental Engineering, Louisiana State University, Baton Rouge, LA 70803, USA
}

Correspondence should be addressed to Guifeng Zhao; gfzhao@zzu.edu.cn

Received 31 December 2019; Revised 2 March 2020; Accepted 11 March 2020; Published 9 April 2020

Guest Editor: Guian Qian

Copyright $\odot 2020$ Zhongfei Ye et al. This is an open access article distributed under the Creative Commons Attribution License, which permits unrestricted use, distribution, and reproduction in any medium, provided the original work is properly cited.

Herein, a three-dimensional (3D) finite element model of a strain clamp-conductor system is established, with an NY-300/40 compression-type strain clamp taken as an example. The tensile load-carrying capacity of the strain clamp under standard crimping conditions is analyzed with LS-DYNA software, and the simulation results are compared with the experimental results to verify the accuracy of the model. On this basis, the tensile load-bearing capacity and failure mode of the strain clamp-conductor system are analyzed when the crimping length between the steel anchor and steel core is insufficient. Studies have shown that the grip strength of a strain clamp is provided mainly by the crimping between the steel anchor and the steel core. Under standard crimping conditions, the tensile load-bearing capacity of the strain clamp can meet the design requirements. Moreover, because the crimping length between the steel anchor and steel core is sufficient, the strain clamp fails due to aluminum strand breakage rather than the steel core being pulled out of the steel anchor. When the crimping length is insufficient, the grip strength of the strain clamp decreases with decreasing crimping length. Although the absolute value of the grip strength does not decrease significantly, the failure mode gradually changes from the breakage of the aluminum strands to the steel core being pulled out of the steel anchor. For the NY-300/40 compression-type strain clamp, the corresponding critical crimping length (i.e., when the change in failure modes occurs) between the steel core and the steel anchor is $50 \sim 60 \mathrm{~mm}$.

\section{Introduction}

Power and energy systems are important lifeline engineering infrastructures that are vital to the stability and sustainable development of society. A typical power supply system consists of three principal components, namely, a power station, transmission lines, and a distribution system. Due to the large scale and complex structural hierarchy, a wide variety of events (e.g., material properties, load variations in usages, and human and natural threats) can cause disruption of a power system [1-3]. Therefore, it is of great significance to carry out studies in the field of safety and reliability of power and energy systems. Among them, studies on the failure mechanisms and lifetime prediction of engineering materials and structures are critical, as they play a basic role in power and energy systems. Scholars have also conducted fruitful research on this issue. Related studies have involved mainly the fatigue and fracture performance of the structure materials in power plants [4-11], the seismic behavior of electric substation equipment and structures [12-14], and wind-induced vibration effects of transmission lines and towers [15-17]. In addition, there have been many other studies that are not listed here. These studies have provided effective technical support for the appropriate design and maintenance of power and energy systems.

In recent years, the continuously increasing power demand has brought on the augmentation of power system capacity and the interconnection of electrical networks. As a 
result, long-distance, large-span, and ultrahigh-voltage (UHV) power transmission systems have emerged. With the formation of the UHV transmission and bulk power system, the safety, stability, and reliability of the power system and its components are required to reach a higher level. Currently, UHV transmission projects often use high-hanging, multisplit steel-cored aluminum stranded conductors with a large cross section as transmission conductors to improve the current-carrying capacity. Thus, the wind-induced tension effects on transmission lines have become even more prominent, incurring high requirements for the tensile strength of a conductor and the fixed strain clamps (Figure 1) connected to it.

As important components of a power transmission system, fixed strain clamps are commonly used to fix conductors and ground wires to insulators or link fittings to tower arms and substation structures. In practice, fixed strain clamps are also called compression-type strain clamps, which are made from materials with a high tensile strength to ensure the safety of the conductors, and hydraulic crimping construction technology is frequently used. However, due to the uncertain factors in the process of crimping and the complex service environment, the failure risk of a strain clamp-conductor system is further increased. In the routine maintenance of power grid lines, it is not uncommon for a line to drop and the metal fittings to fall off due to strain clamp failure (breakage or cracks), causing a serious threat to the safety of power transmission systems. Therefore, it is essential to conduct research on the quality of crimping and mechanical performance of hydraulic strain clamp-conductor systems to ensure that they can operate safely within their design service periods.

Researchers have carried out a series of simulation and experimental studies on different aspects, such as the crimping process and quality, clamp defect detection, and stress analyses of the clamp and wire. In terms of the crimping process and quality, Chanda et al. [18] analyzed the effects of a circular stamper and a square stamper on the crimping process and noted that the stress state of the aluminum alloy after crimping with the circular stamper is better than that after crimping with the square stamper. Abbas et al. [19] conducted a twodimensional simulation of the crimping process using implicit and explicit finite element methods; they compared their simulation results with experimental data from an actual crimping process. Shirgaokar et al. [20] analyzed the crimping process between a double-grooved tube and a bullet, in which they investigated the issues associated with different crimping processes, manufacturing tolerances, and stress distributions. The studies of Liu et al. [21] showed that incomplete surface cleaning or poor high-current drainboard installation in the crimping process could generate a large amount of heat, leading to a reduction in the strength of the steel core and causing a disconnection accident. He et al. [22] analyzed the mechanisms governing the breakage of a $750 \mathrm{kV}$ line with improperly crimped strain clamps. Their analysis showed that the main cause of the line breakage was the poor crimping quality of the aluminum pipe and the steel anchor in the strain clamp. The effects of different crimping methods between an aluminum pipe and a steel anchor on the grip strength of a

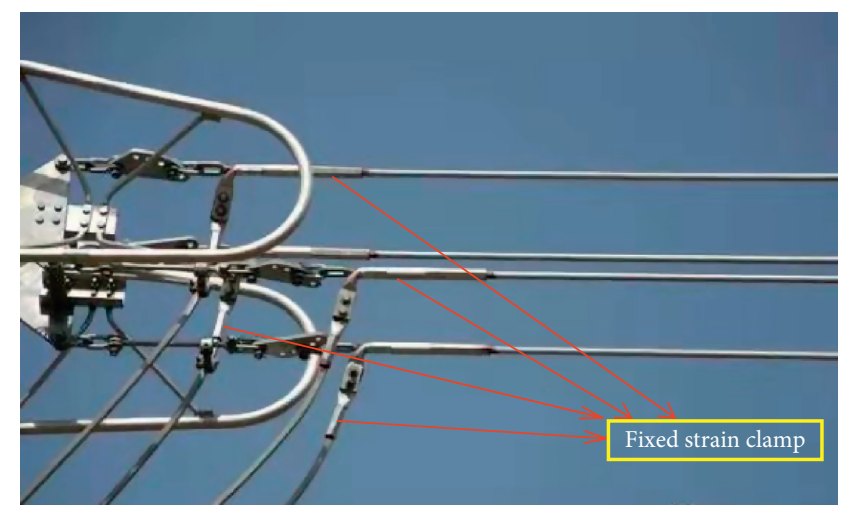

FIgURE 1: Connection diagram of a strain clamp for an overhead transmission line.

strain clamp were studied in depth by Sun et al. [23], and their results showed that a correct crimping technique is critical to ensure that the strain clamp has a sufficient grip strength. In addition, researchers have also investigated the crimping length of strain clamps. Feng et al. [24] investigated the crimping length of large cross section conductors $\left(1520 \mathrm{~mm}^{2}\right)$ and strain clamps, through which they determined the critical crimping lengths between the strain clamps and the aluminum pipe and steel anchor. However, this study did not analyze the failure modes or internal stresses under different crimping lengths between the wire and the aluminum pipe and steel anchor. In terms of defect detection for the strain clamp and wire, the research results focus mainly on the application of nondestructive testing technology. Rizzo and Di Scalea [25] and Cramer et al. [26] successfully used ultrasonic detection techniques to study the crimping quality of cables and strain clamps. Finc et al. [27] used a thermal image diagram to evaluate the quality of a strain clamp. In recent years, researchers have employed X-ray nondestructive testing technology to detect defects in strain clamps and wires. For example, Wang et al. [28] and Rajak and Kore [29] successfully applied this technology in the analysis and evaluation of the crimping quality of a strain clamp. Wang et al. [30] theoretically analyzed the feasibility of using this technology in transmission lines, determined the different defect conditions via field X-ray detection and tensile tests, and provided a reliable basis for the use of X-rays to measure the quality of crimping of fittings.

Compared with the above two aspects, there are relatively many studies focusing on wire stress analysis. Most of these studies have focused on the simulation of the stress characteristics of stranded wires while considering the influence of the contact of the strands and the damage and fatigue failure of the wires. For example, Kumar and Botsis [31] studied the behavior of multilayered strands with metallic fiber cores under the action of axial tension and combined axial tension-torsion and proposed a corresponding analytical expression for the maximum contact stress. Jiang et al. [32] established an effective finite element model to predict the mechanical properties of steel strands with multicontact modes. Ghoreishi et al. [33] compared the numerical simulation results from 9 linear elastic analytical 
models and a three-dimensional finite element model of a single-layered strand under static axial loading. Levesque et al. $[34,35]$ simulated the contact relationship between a wire and a suspension clamp using an elliptical elastoplastic microcontact model. Kalombo et al. [36] evaluated the cause of premature fatigue failure of an AAAC 900 MCM conductor used on a $230 \mathrm{kV}$ power line in the central-west region of Brazil. The above studies provide a good basis for an in-depth analysis of the mechanical properties of a strain clamp-conductor system.

A summary of the above literature shows that there are an increasing number of problems related to the failure of strain clamps in practice, especially mechanical damage, and this issue has become a focus of attention in transmission line engineering. Therefore, an in-depth investigation of the tensile load-bearing capacities and failure modes of a hydraulic strain clamp-conductor system is of great significance. However, to our knowledge, there has been relatively little research on the overall tensile performance of a strain clamp-conductor system after crimping due to the difficulty of obtaining the internal stress-strain information of a closed strain clamp-conductor system through tests. Therefore, in this paper, an NY-300/40 compression-type strain clamp is used as an example to simulate the tensile behavior of the strain clamp-conductor system after crimping. The variation characteristics of the tensile load-bearing capacity of this system and the corresponding failure modes of the system under different crimping lengths are analyzed. The results may provide an approximate prediction of the load-carrying capacity and safety of a strain clamp-conductor system.

\section{Finite Element Model for a Typical Strain Clamp-Conductor System}

A typical compression-type strain clamp is composed mainly of steel anchors and aluminum casings, as shown in Figure 2, and the steel anchors are used to connect the steel core in the inner layer of aluminum cable steel-reinforced (ACSR) conductors. The two ends of the aluminum pipe are crimped with an aluminum strand and steel anchor so that the strain clamp and the steel-cored aluminum strand are fixed together to form an overall structure capable of withstanding the full tension of the conductor. Considering that the NY-300/40 compression-type strain clamp is commonly used in transmission lines, the following analysis is based mainly on this type of strain clamp.

2.1. Geometrical and Material Parameters. The NY-300/40 strain clamp is suitable for crimping LGJ-300/40 steel-cored aluminum stranded wires, and this type of wire has four layers. The first and second layers are steel cores with 1 strand and 6 strands, respectively, wherein the diameter of a single strand is $2.66 \mathrm{~mm}$. The third and fourth layers are aluminum stranded wires with 9 strands and 15 strands, respectively, wherein the diameter of a single strand is $3.99 \mathrm{~mm}$. The geometric constructions of the steel-cored aluminum stranded wire, steel anchor, and aluminum pipe are shown in Figure 3. Table 1 lists the mechanical properties of each component material under normal temperature and pressure. The corresponding stress-strain curves of each material are shown in Figure 4.

2.2. Mesh Generation. To accurately simulate the mechanical properties of the strain clamp-conductor system, the finite element preprocessing software HyperMesh [37] is used in this paper to establish the 3D simulation model (Figure 5), generate the mesh, and build the finite element model. Because the shapes of the steel core wire, aluminum stranded wire, aluminum pipe, and stamper are relatively simple and regular, hexahedral elements are used for meshing. Compared with tetrahedral elements of the same size, hexahedral elements have a higher accuracy and higher computational efficiency. For the steel anchor, because the steel anchor groove has a sharp angle, it is not suitable for splitting into hexahedral elements. Therefore, the steel anchor is divided into two parts. The joint with the steel core wire uses hexahedral elements, and the joint with the aluminum pipe uses tetrahedral elements. For the interface of the two parts, the common node method is used with a unit size of $1 \mathrm{~mm}$. Figures 6-8 show the meshing diagrams of the steel core wire, aluminum stranded wire, steel anchor, and aluminum pipe.

For the stamper, the deformation is very small during the crimping process, and rigid body simulation is used in the modeling. Figures 9-11 show finite element models of the stamper with the steel core, steel anchor, aluminum pipe, and aluminum strand.

2.3. Calculation Settings. The crimping and stretching of the strain clamp-conductor system are both completed in a relatively short time, and a relatively large plastic deformation occurs during the process. Since these processes are highly nonlinear and are not statically balanced, this paper selects the powerful LS-DYNA finite element software [38] for the simulation analysis. LS-DYNA is a general-purpose finite element program capable of simulating complex realworld problems. The core competency of this software lies in highly nonlinear transient dynamic finite element analysis using explicit time integration. During computation, the central difference method, which has relatively high calculation efficiency and accuracy, was also used to improve computational efficiency. Corresponding to the aforementioned preprocessing model, all meshes adopt SOLID164 elements.

When establishing the material model, after considering the entire loading process of the material (from initial deformation to yielding, strengthening, and fracture) and the eventual failure of the strain clamp, a piecewise linear model for an elastoplastic material is selected; the keyword for this model is *MAT_PIECEWISE_LINEAR_PLASTICITY. To accurately simulate failure when the stress exceeds the strength limit of the material, a material failure criterion was added (*ADD_MAT_EROSION), in which the criterion was set as an effective stress. Thus, in the calculation process, when the stress value corresponding to a certain unit reaches the corresponding material strength limit, this unit could be 


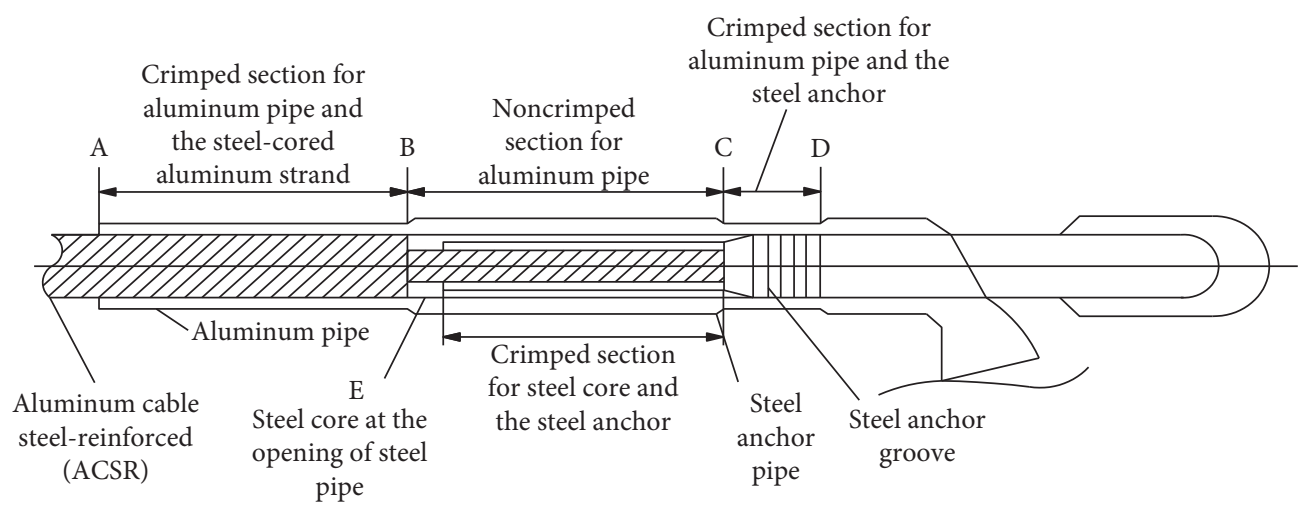

Figure 2: Typical compression-type strain clamp.

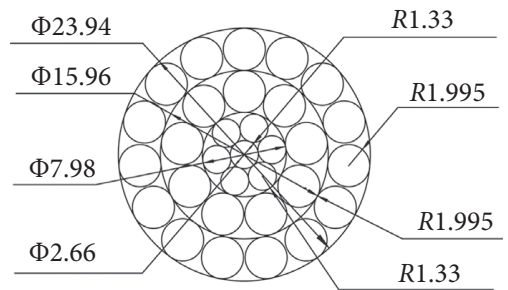

(a)

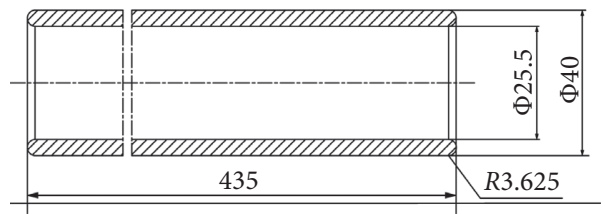

(b)

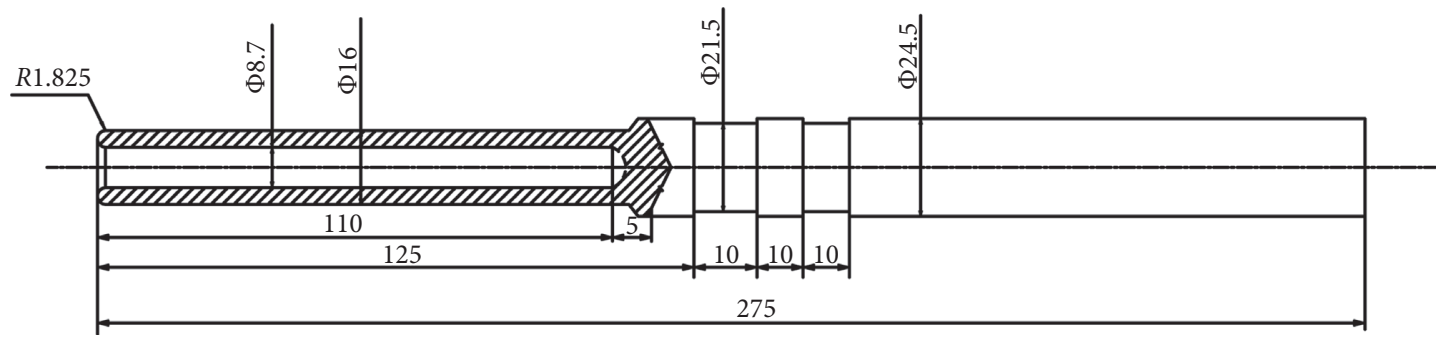

(c)

FIGURE 3: Schematic diagram of the geometric construction of an NY-300/40 strain clamp: (a) cross section of the steel core and aluminum strands; (b) aluminum pipe; (c) steel anchor.

TABLE 1: Mechanical properties of the strain clamp and conductor materials.

\begin{tabular}{lccccc}
\hline Parts & $\begin{array}{c}\text { Young's modulus } \\
(\mathrm{MPa})\end{array}$ & $\begin{array}{c}\text { Poisson's } \\
\text { ratio }\end{array}$ & $\begin{array}{c}\text { Density }\left(\mathrm{kg} / \mathrm{m}^{3}\right) \\
\text { Yield strength Tangent modulus } \\
(\mathrm{MPa})\end{array}$ & $\begin{array}{c}\text { Tensile strength } \\
(\mathrm{MPa})\end{array}$ \\
\hline Steel core & $1.95 \times 10^{5}$ & 0.3 & 7850 & 1210 & 6100 \\
Steel anchor and stamper & $2.03 \times 10^{5}$ & 0.3 & 7850 & 235 & 6100 \\
Aluminum pipe and aluminum wire & $7 \times 10^{4}$ & 0.31 & 2703 & 125 & 2200 \\
\hline
\end{tabular}

deleted, resulting in a failure effect. Take the aluminum stranded wires for example: in the stretching process, when the stress value of a certain unit in one aluminum wire reaches $187 \mathrm{MPa}$, this unit is considered a failure unit and should be deleted. Consequently, if all the units on the same cross section of one aluminum wire in the aluminum strand are removed due to failure, the strand breaks.

For the stamper, the rigid material model ( ${ }^{*}$ MAT_RIGID) is used. In addition, to ensure the smooth progression of the central difference algorithm used in the calculation, the same material parameters used for the steel anchor are assigned to the stamper. There are two types of contact in the crimping process of the strain clamp-conductor system. The first contact type is a contact existing prior to crimping, including the mutual contact between the steel core wire and aluminum strands. In the process of kinetic analysis, it is assumed that there is no mutual penetration or separation between the steel core wires and the aluminum strands; i.e., the core wires and strands can only slide along their respective interfaces. This is a typical two-way face-to-face contact. However, due to the large number of contact surfaces between these objects, it is not 


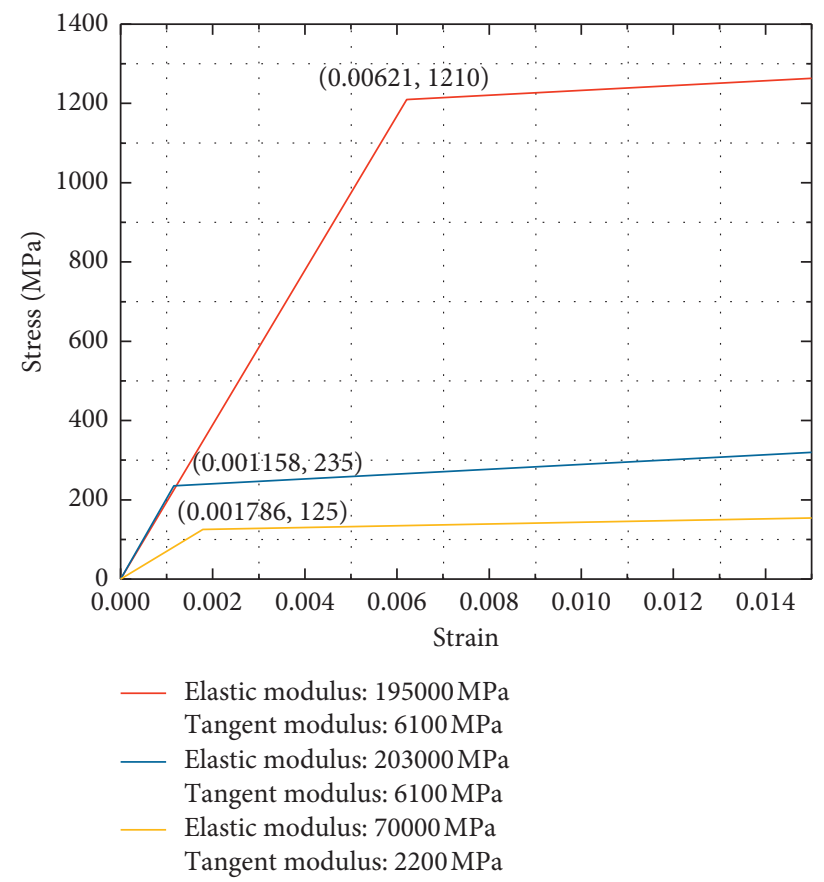

FIGURE 4: Stress-strain curves of the strain clamp and conductor materials.

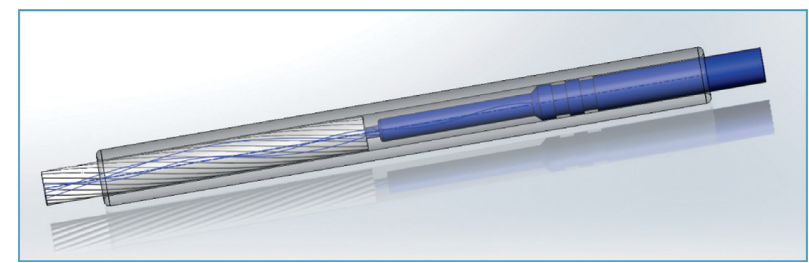

Figure 5: The 3D simulation model of the strain clamp-conductor system.

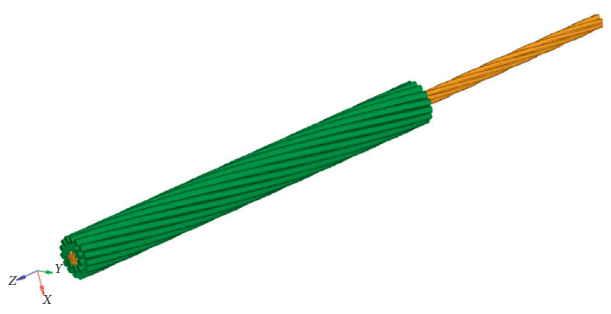

(a)

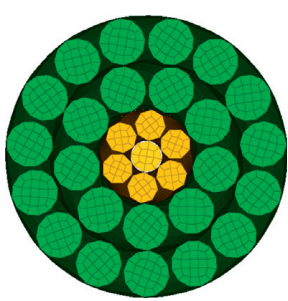

(b)

Figure 6: Meshing diagram of the steel core wire and aluminum stranded wire: (a) overall view; (b) cross-sectional view.

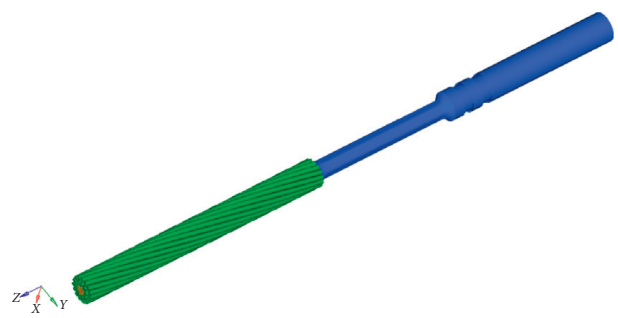

Figure 7: Meshing diagram of the steel anchor (left side: steel-cored aluminum stranded wire). 


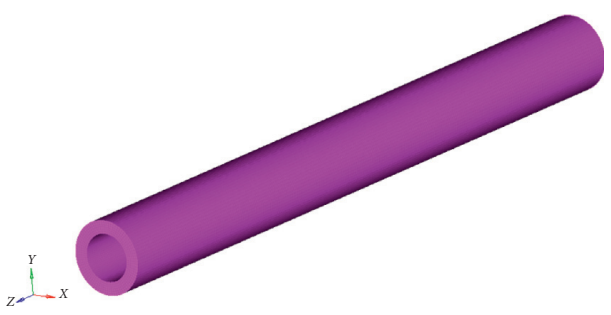

(a)

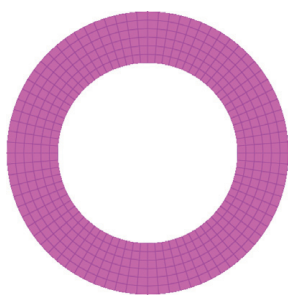

(b)

Figure 8: Meshing diagram of the aluminum pipe: (a) overall view; (b) cross-sectional view.

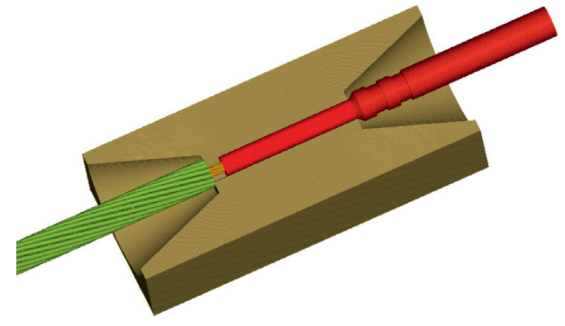

(a)

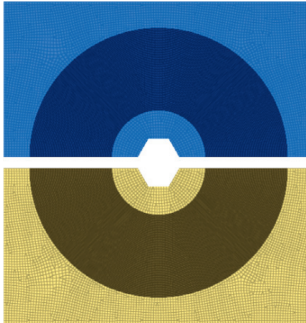

(b)

Figure 9: A finite element model for the crimping process of the stamper, steel core, and steel anchor: (a) overall view; (b) cross-sectional view.

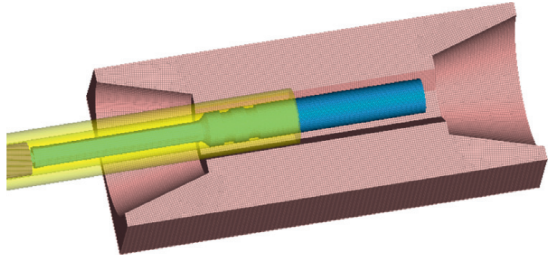

(a)

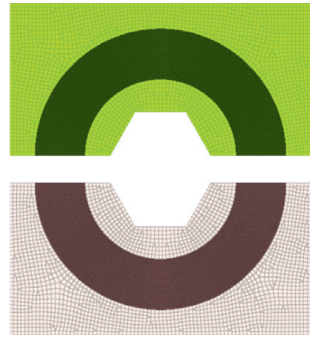

(b)

Figure 10: A finite element model for the crimping process of the stamper, aluminum pipe, and steel anchor: (a) overall view; (b) crosssectional view.

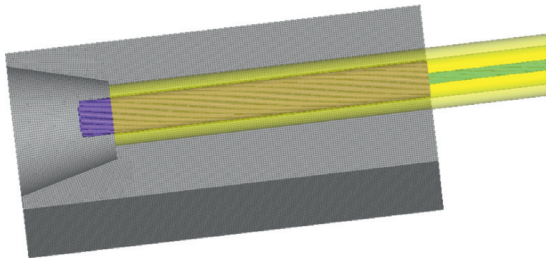

(a)

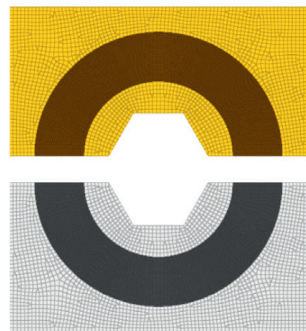

(b)

FIGURE 11: A finite element model for the crimping process of the stamper, aluminum pipe, and aluminum strand: (a) overall view; (b) crosssectional view.

easy to determine all the contact surfaces in the entire simulation process. Therefore, for the simulation in this paper, an automatic face-to-face contact model is selected to search the contact surfaces; the keyword for the model is
${ }^{*}$ CONTACT_AUTOMATIC_GENERAL [39, 40]. The second contact type is the contact that occurs after the relative movement of the components due to the crimping process, including the contact between the steel core and the 
steel anchor, the contact between the steel anchor and the aluminum pipe, the contact between the aluminum pipe and the aluminum strand, the contact between the steel anchor and the stamper, and the contact between the aluminum pipe and the stamper. These contacts are also two-way faceto-face contacts. However, because these contact surfaces can be specified, the contact surfaces are noted with the ${ }^{*}$ CONTACT_AUTOMATIC_SURFACE_TO_SURFACE keyword during analysis.

The grip strength of the strain clamp is derived mainly from the friction between the contact surfaces. For example, the binding force between the steel anchor and the steel core wire is the most important part of the grip strength of the strain clamp. This part of the binding force is the friction from the contact surface between the steel anchor and the steel core wire. In the present study, the friction from the contact surfaces is considered by setting the friction coefficient in all contact keywords. The friction coefficients were set to 0.2 for simulating the contact behavior between the steel and aluminum materials. Note that there is no precompression between the contact surfaces.

In the stretching simulation, the application of the stretching boundary condition also includes two aspects: the application of the tensile load and the application of the corresponding boundary constraint. During the stretching process, the side end of the steel anchor is fixed and constrained, and then the tensile load is applied on all the side ends of the steel-cored aluminum strands. Considering the uniqueness of the structure of the steel-cored aluminum stranded wire, the cross section of each steel strand is not perpendicular to the axial direction of the aluminum strand. Although the tensile load is applied axially during stretching, the actual load is applied on a protruding strand. Therefore, in this paper, a special method is used to apply a tensile load to the steel-cored aluminum stranded wires. First, the node on the short segment near the end of the steel-cored aluminum strand is selected and set as a rigid body constraint, for which the keyword is *CONSTRAINED_NODAL_RIGID_BODY. The constraint target is set as a node on the strand axis. Hence, the selected nodes do not undergo relative displacement during the stretching process but undergo only rigid body displacement; the corresponding movement can be specified by the target node. Then, the target node is subjected to a tensile load in a specified direction (i.e., the load along the axial direction), for which the keyword is * LOAD_RIGID_BODY. Thus, in the analysis, the tension can be manually applied and gradually increased from 0 to a relatively large value within a certain period of time until the strain clamp fails. Boundary constraints are applied to the side ends of the steel anchor. In contrast to the application of the tensile load, the cross section of the steel anchor end is round and perpendicular to the axis. Therefore, it is necessary only to apply the boundary constraints to the cross sections on the side ends of the steel anchor to achieve the same effect as the fixed constraint. Therefore, in this study, all nodes on the cross sections of the side ends of the steel anchor are selected, and then node constraints are applied to limit the degree of freedom in all directions during the stretching process, for which the keyword is *CONSTRAINED_SPC_SET. Thus, during the entire stretching process, the cross sections of the side ends of the steel anchor remain constrained and cannot move or deform.

In addition, for the eight-node first-order reduced integration elements, when performing a nonlinear dynamic analysis, the hourglass mode is prone to occur, distorting the calculation results. Therefore, hourglass control parameters need to be added to the model, for which the keyword is *CONTROL_BULK_VISCOSITY. For the simulation analysis in this paper, the stiffness type of hourglass control is selected, and the hourglass control parameters are appropriately reduced to obtain better calculation results.

\section{Analysis of the Tensile Load-Bearing Capacity and Failure Mode of the Strain Clamp- Conductor System under Standard Crimping Conditions}

3.1. Regulations Related to Standard Crimping. The code of hydraulic crimping process specification for overhead conductors (below $800 \mathrm{~mm}^{2}$ ) and ground wires in transmission and transformation project construction (DL/T 5285-2018)

[41] specifies the corresponding crimping length for each part in the strain clamp. For an NY-300/40 compressiontype strain clamp, the standard crimping length between the steel anchor and steel core is $110 \mathrm{~mm}$, whereas the crimping length between the aluminum pipe and aluminum strand is $190 \mathrm{~mm}$.

According to the codes of strain clamp (DL/T 757-2009) [42] and general technical requirements for electric power fittings (GB/T 2314-2008) [43], the grip strength of the compression-type strain clamp should not be less than $95 \%$ of the rated tensile strength (RTS) of the corresponding wire. According to the code of round wire concentric lay overhead electrical stranded conductors (GB/T 1179-2008) [44], the RTS of the LGJ-300/40 conductor is $92.36 \mathrm{kN}$. Therefore, the grip strength of an NY-300/40 strain clamp should not be lower than $92.36 \mathrm{kN} \times 95 \%=87.742 \mathrm{kN}$. In practice, whether the abovementioned grip strength can be achieved is also an important basis for judging crimping quality.

Based on Table 1 and Figure 3(a), the tensile strength of the LGJ-300/40 steel core is $1558 \mathrm{MPa}$, and the cross section is $38.9 \mathrm{~mm}^{2}$. The calculated breaking load for the steel core in the inner layer is $60.61 \mathrm{kN}$, which is approximately $69.07 \%$ of the designed grip strength of the clamp. Therefore, the tensile strength of the steel core has an important impact on the grip strength of the strain clamp. In practice, effective crimping between the steel anchor and the steel core is of great significance to fully utilize the tensile properties of the steel core, which could further ensure the grip strength of the strain clamp.

\subsection{Comparison of Finite Element Simulation and Experi-} mental Results. The stretching process of the strain clampconductor system under standard crimping conditions (i.e., the crimping length between the steel anchor and steel core is $110 \mathrm{~mm}$ ) is simulated and analyzed. A continuous tensile load is applied until the clamp breaks or fails. The recorded 
breaking force is $95.472 \mathrm{kN}$, which exceeds the specified maximum grip strength of $87.74 \mathrm{kN}$, indicating that the strain clamp can meet the requirement of the grip strength under the standard crimping conditions.

To verify the reliability of the aforementioned simulation results, this research also conducts a stretching test on 4 defectless NY-300/40 strain clamps under standard crimping conditions [45]. The test strain clamps were randomly chosen from a batch of products of regular manufacturers. A sampling detection result of the chemical composition of the test pieces is demonstrated in Table 2. The results indicate that the chemical compositions of the strain clamps meet the requirements of the code of wrought aluminium and aluminium alloy-chemical composition (GB/T 3190-2008) [46].

The tensile test conditions are as follows: $20 \pm 1^{\circ} \mathrm{C}$ indoor air temperature, $60 \%$ relative humidity, and standard atmospheric pressure. The loading method is as follows: (a) fix the strain clamp-conductor system to the tensile testing device and adjust the system to an appropriate position. (b) Gradually apply the tensile load to $46.18 \mathrm{kN}, 60 \mathrm{kN}, 80 \mathrm{kN}$, and $87.74 \mathrm{kN}$ and hold the load for 120 seconds. If a strand breakage or slip occurs during the loading process, the corresponding load at that time is recorded. (c) Gradually apply the tensile load until the strain clamp-conductor system fails. During the stretching tests, the tensile loads and tensile displacements of the end of the aluminum pipe in the $Z$-direction are collected automatically with a computer system.

Taking test piece 1 as an example, the breaking force for this test piece is $94.026 \mathrm{kN}$ (Figure 12). For the other test pieces, the measured breaking forces are $95.954 \mathrm{kN}$, $96.626 \mathrm{kN}$, and $92.490 \mathrm{kN}$, as shown in Table 3. A comparison of the simulated load-displacement curve and the experimental results is shown in Figure 13. The simulated and experimental load-displacement curves have similar shapes, and the simulated breaking force is also consistent with the test results with a maximum deviation of $3.12 \%$.

After testing, to observe the deformation inside the clamp, the aluminum pipe in the outer layer of one test piece is cut open. The internal deformation after the crimping of the aluminum pipe and the aluminum strand is shown in Figure 14(a), and the corresponding finite element simulation results are shown in Figure 14(b). The simulation results in this study are consistent with the physical morphology. During the stretching process, the aluminum pipe is plastically deformed under the compression of the stamper and the aluminum strand, and the inner wall exhibits a threaded shape.

In summary, the finite element model established in this paper has relatively high reliability and can be used for the further analysis of the characteristics of the tensile loadbearing capacity of the strain clamp-conductor system.

\subsection{Analysis of the Stress Characteristics of Various Compo-} nents during the Stretching Process. To understand the stress characteristics of each component of the strain clampconductor system during the stretching process, four typical tensile working conditions, namely, 25\% RTS, 50\% RTS,
95\% RTS, and the ultimate load, are extracted for a comparative analysis. In particular, $25 \%$ RTS is the tension experienced by the wires when the line is operating normally.

\subsubsection{Stress Analysis of the Aluminum Strand. Figure 15} shows the stress distribution of each aluminum strand during each stage of the stretching process.

When the tensile load does not exceed 50\% RTS, the stress in most areas of the aluminum strand is in the elastic range (Figures 15(a) and 15(b)). When the tensile force increases to $95 \%$ RTS, the stress level of the aluminum strand in the area near the end of the aluminum pipe is relatively high, and relatively, large plastic deformation occurs (Figure 15(c)). The maximum stress in the strand is $172.6 \mathrm{MPa}$, which is close to the tensile strength limit of $187 \mathrm{MPa}$. The maximum stress in the aluminum strand in the crimping area away from the aluminum pipe end is approximately $150 \mathrm{MPa}$, which is still within the safe range. The preliminary analysis shows that, in the crimping area, due to the frictional and mechanical forces caused by crimping, the aluminum pipe and the aluminum strand jointly assume the tensile loading effect. The tensile load is reduced or even disappears near the end of the aluminum pipe due to the constraints, and the aluminum strand takes up the most tensile load. Therefore, the stress in the aluminum strand near the outlet of the aluminum pipe is significantly high. As the tensile load continues to increase to $95.472 \mathrm{kN}$, some aluminum strands near the end of the crimped area of the aluminum pipe are already broken (Figure 15(d)), while the stress level of the remaining aluminum strands continues to increase until the strands are broken. This outcome indicates that, under the ultimate load, the outer aluminum strands have lost their bearing capacity.

To illustrate the characteristics of the fracture development of the aluminum strand more clearly, Figure 16 shows stress nephograms of the cross section of the aluminum strand at the fracture location under different tensile loading levels.

When the tensile load is $25 \%$ RTS, the stress in the inner aluminum stranded wire is relatively small and is in the elastic range; in contrast, the aluminum strand in the outer layer has a relatively large stress, and this strand has already experienced local plastic deformation. When the tensile load increases to $50 \%$ RTS, the stress shows a certain uniformity along the circumferential direction, and the stress in the inner layer is slightly larger than that in the outer layer. When the load is 95\% RTS, the entire cross section has undergone plastic deformation, and the stress distribution is relatively uniform, close to the fracture limit. Moreover, the cross-sectional area of the three aluminum strands in the outer layer is slightly reduced due to necking. When the ultimate load is reached, the three previously collapsed aluminum strands are all broken and can no longer bear any load. Thus, the load on the other 21 aluminum strands suddenly increases, resulting in the necking phenomenon. The 12 aluminum strands in the outer layer all show obvious 
TABle 2: Chemical compositions of the strain clamps (mass fraction).

\begin{tabular}{lccccccc}
\hline Test piece & $\mathrm{Si}$ & $\mathrm{Fe}$ & $\mathrm{Cu}$ & $\mathrm{Mn}$ & $\mathrm{Mg}$ & $\mathrm{Zn}$ & $\mathrm{Al}$ \\
\hline 1 & 0.19 & 0.12 & 0.03 & 0.04 & 0.03 & 0.003 & 99.6 \\
2 & 0.20 & 0.14 & 0.03 & 0.03 & 0.03 & 0.005 & 99.6 \\
3 & 0.20 & 0.13 & 0.04 & 0.03 & 0.02 & 0.006 \\
4 & 0.17 & 0.12 & 0.02 & 0.01 & 0.02 & 0.005 & 99.6 \\
Nominal value & $\leqq 0.25$ & $\leqq 0.40$ & $\leqq 0.05$ & $\leqq 0.05$ & $\leqq 0.05$ & $\leqq 0.07$ & $\geqq 99.7$ \\
\hline
\end{tabular}

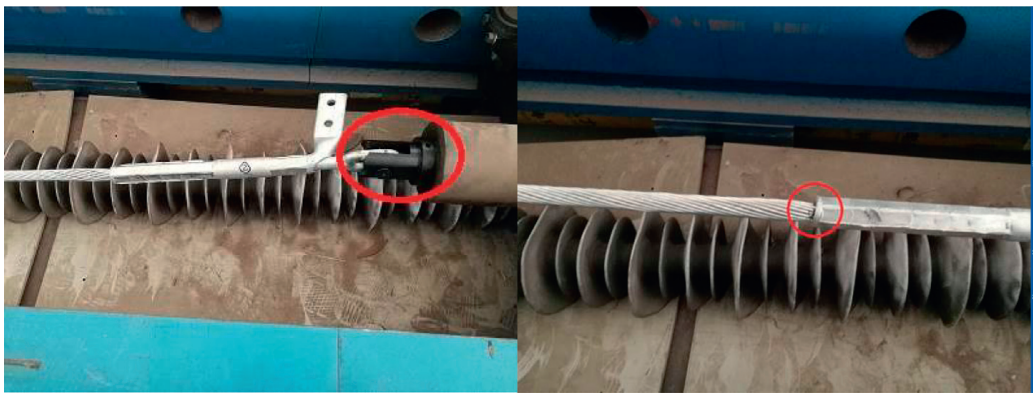

(a)

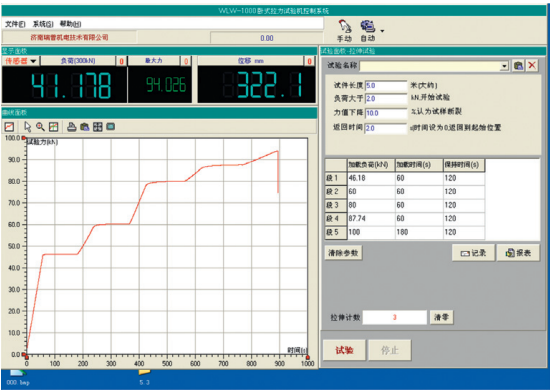

(b)

FIGURE 12: Stretching test for the strain clamp-conductor system: (a) gripping device for the strain clamp and the breaking position of the wire; (b) load data for test piece 1 at each step.

TABLE 3: Comparison of breaking forces between simulation results and experimental results.

\begin{tabular}{lccc}
\hline \multirow{2}{*}{ Test piece } & \multicolumn{2}{c}{ Breaking forces $(\mathrm{kN})$} & Relative deviation $(\%),|(a)-(b) /(a)| \times 100 \%$ \\
\hline 1 & Simulation results $(\mathrm{a})$ & Experimental results $(\mathrm{b})$ & 1.51 \\
2 & 95.472 & 94.026 & 0.50 \\
3 & 95.472 & 95.954 & 1.21 \\
4 & 95.472 & 96.626 & 3.12 \\
\hline
\end{tabular}

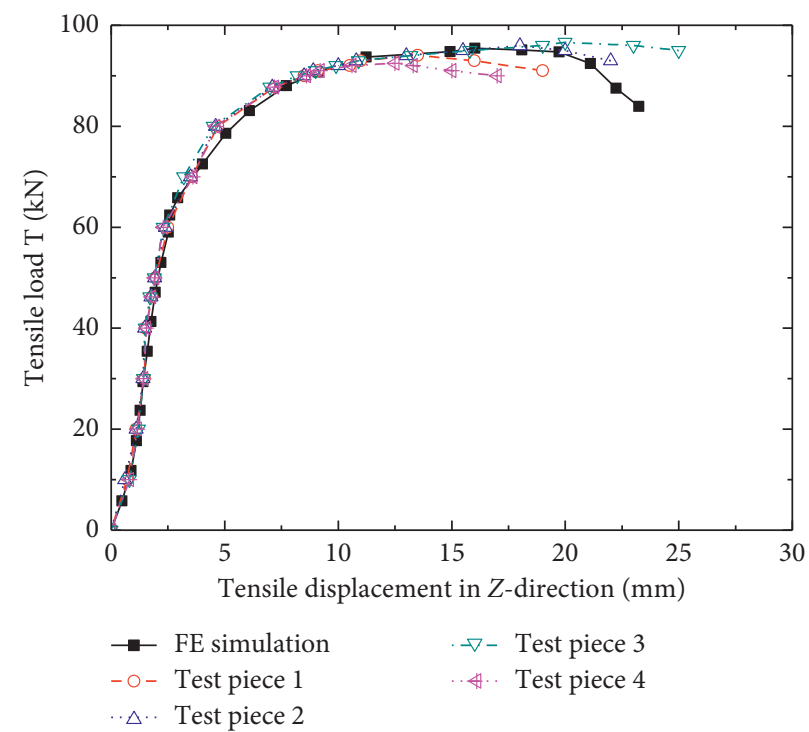

FiguRE 13: Comparison of the simulated load-displacement curve and the experimental results under standard crimping conditions. 


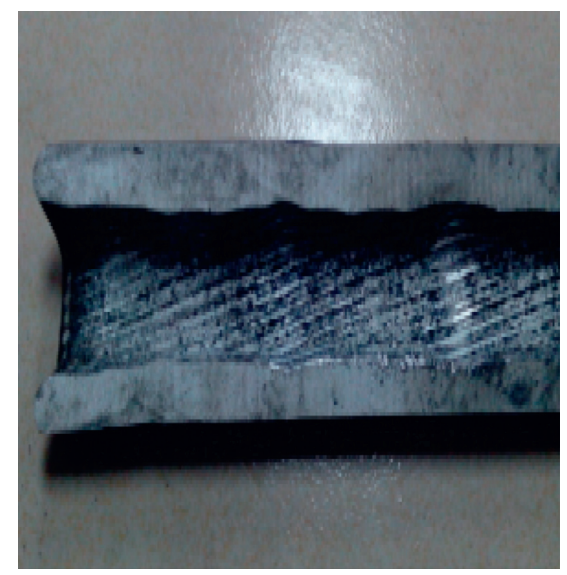

(a)
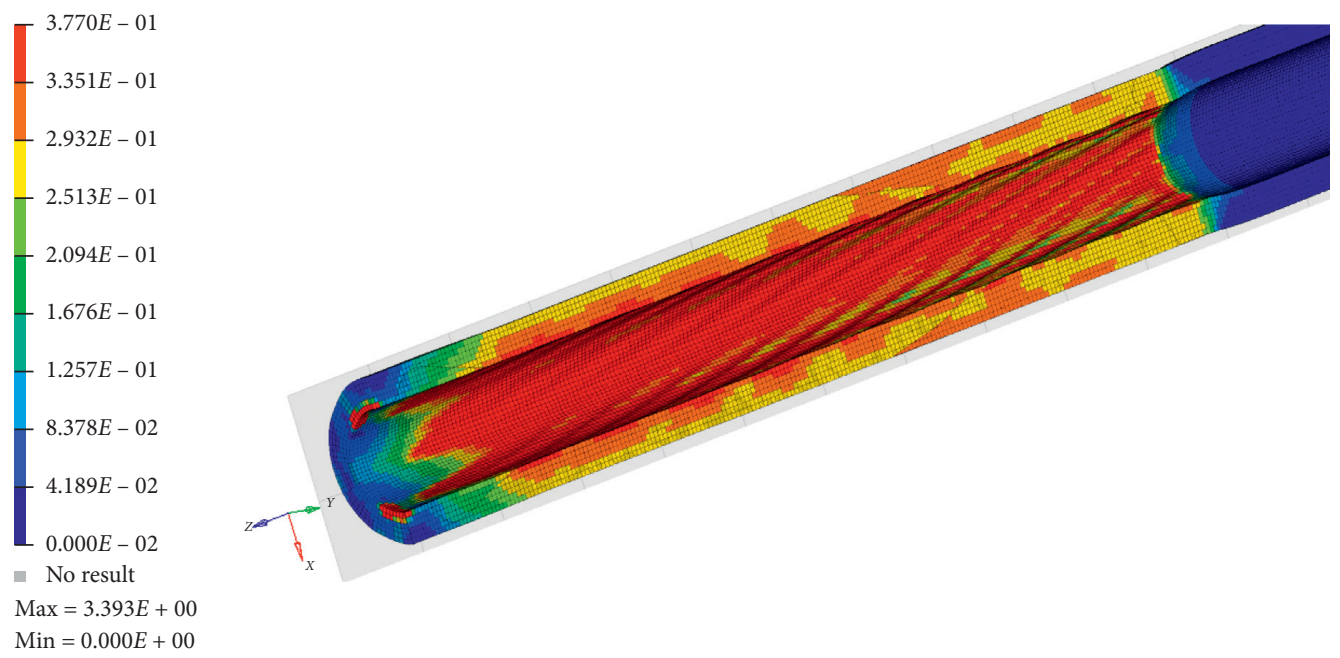

(b)

Figure 14: Crimping deformation between the aluminum pipe and the aluminum strand: (a) actual deformation; (b) finite element simulation of deformation.

necking, and the cross-sectional area decreases by more than $50 \%$. In contrast, the 9 aluminum strands in the inner layer show no obvious necking, indicating that the breakage of the aluminum strand gradually developed from the outer layer to the inner layer.

\subsubsection{Stress Analysis of the Steel Core. Figure 17 shows the} stress distribution of the steel core under different tensile loading levels. When the tensile load is $25 \%$ RTS or $50 \%$ RTS, the difference in the stress in the steel core is not significant, and the stress in the whole steel core is within the elastic range. When the tensile load increases to 95\% RTS, the maximum stress in the inner steel core inside the crimped area of the aluminum pipe increases to $1257 \mathrm{MPa}$, which is slightly greater than its yield strength of $1210 \mathrm{MPa}$. In contrast, the maximum stress in the inner steel core inside the crimped area of the steel anchor and steel core is $978.2 \mathrm{MPa}$, which is within the elastic range. When the ultimate load is reached, the maximum stress in the inner steel core in the crimped area of the aluminum pipe reaches $1482 \mathrm{MPa}$, which is still lower than its ultimate tensile strength of $1558 \mathrm{MPa}$; the maximum stress in the steel core inside the crimped area of the steel anchor and steel core on the other side reaches $989.2 \mathrm{MPa}$, which is still in the elastic range.

The relative positions of the steel core and the steel anchor under the ultimate load can also be seen in Figure 17(d). When the strain clamp is broken due to breakage of the aluminum strand in the crimped area of the aluminum pipe under the ultimate load, the crimping area of the steel anchor and steel core on the other side still maintains a good crimp, and the steel core is not pulled out of the steel anchor. This finding indicates that, under standard crimping conditions, the grip strength of the strain clamp is mainly provided by the crimping between the steel anchor and the steel core, and because the crimping length is sufficient, the frictional force and mechanical force between the steel anchor and steel core can ensure that they are not pulled apart. Therefore, under standard crimping conditions, the failure mode of the strain clamp is aluminum strand breakage instead of the steel core being pulled out of the steel anchor.

3.3.3. Stress Analysis of the Steel Anchor. The stress distribution on the steel anchor at each stage of the stretching 


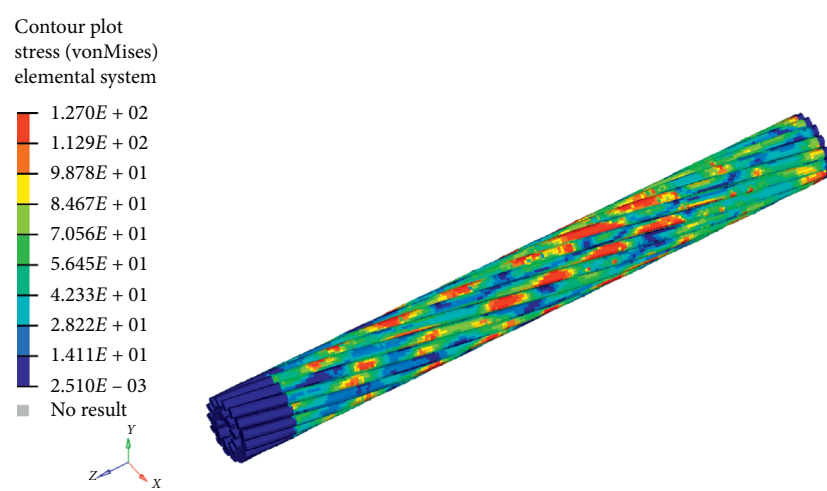

(a)

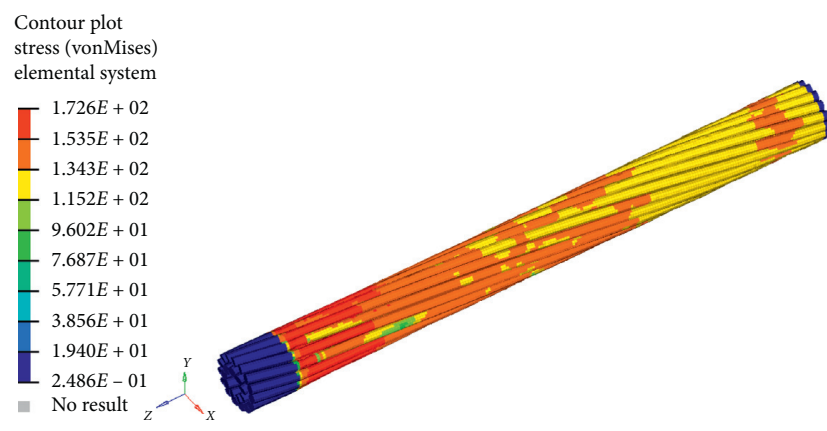

(c)
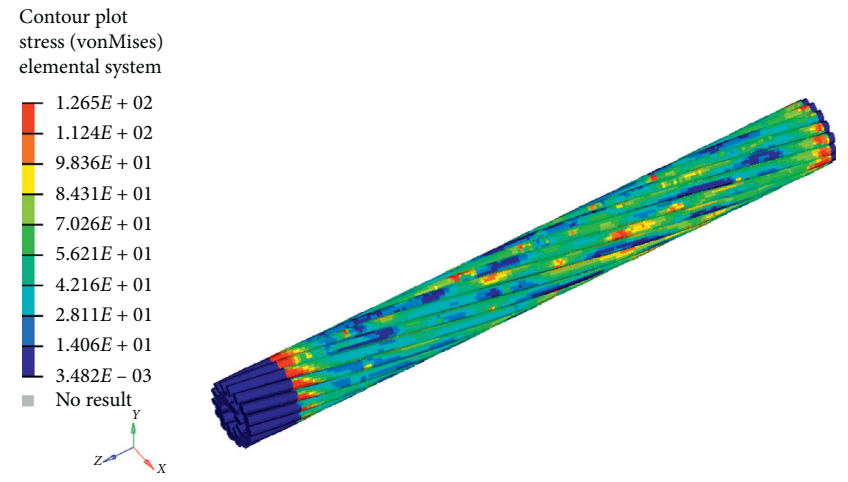

(b)

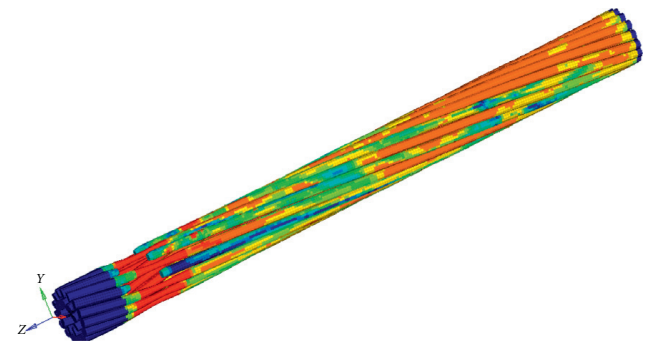

(d)

FIGURE 15: Stress nephograms of aluminum strands in different stretching stages: (a) 25\% RTS; (b) 50\% RTS; (c) 95\% RTS; (d) ultimate load.

process is shown in Figure 18. According to the stress in the steel anchor, the stress in the main body of the steel anchor is in the elastic range during the entire stretching process. Although there are relatively large stresses in the crimped area of the steel anchor and the steel core near the stepped shaft and in the groove root of the crimped area of the steel anchor and the aluminum pipe, the values are lower than the tensile strength of the steel anchor. The above stress distribution also indirectly indicates that the distribution of the grip strength generated by the crimping between the steel anchor and the steel core is not uniform along the axial direction. Moreover, in the crimped area of the steel anchor and the aluminum pipe, due to the "occlusion" between the steel anchor and the aluminum pipe, the stress level in this location is relatively high, which is also the main contributor to the grip strength in the crimped area of the steel anchor and the aluminum pipe.

\section{Analysis of the Failure Mode of the Strain Clamp-Conductor System When the Crimping Length Is Insufficient}

The above analysis has shown that the crimping between the steel anchor and the steel core has a relatively large impact on the grip strength of the strain clamp, so ensuring a sufficient crimping length between the two is of great importance for the safety of the clamp. However, due to the complexity of the shaping and crimping process of the strain clamp and the wire, in practice, the crimping length of the steel core often cannot meet the requirements of regulations due to improper shaping, which also poses a hidden threat to the safety of transmission operations.

To analyze the variation characteristics of the tensile loadbearing capacity of the strain clamp-conductor system when the crimping length between the steel anchor and steel core is insufficient, the simulation analysis in this section uses the parameters of standard crimping conditions as the basis and changes only the crimping length between the steel anchor and steel core $(100 \mathrm{~mm}, 90 \mathrm{~mm}, 80 \mathrm{~mm}, 70 \mathrm{~mm}, 60 \mathrm{~mm}$, and $50 \mathrm{~mm}$ ). The selected lengths not only ensure the range of the crimping length interval but also consider the actual probability of occurrence in practice. Previous calculations [39] have shown that when the crimping length between the steel anchor and steel core is greater than $70 \mathrm{~mm}$, the tensile load-bearing capacity and failure mode of the strain clamp-conductor system are very similar to those under standard crimping situations. Considering the length limitation in this paper, only the results for crimping lengths of $50 \mathrm{~mm}, 60 \mathrm{~mm}$, and $70 \mathrm{~mm}$ are used for the comparative analysis.

4.1. Breaking Force and Load-Displacement Relationship. Figure 19 shows the simulated load-displacement curve when the crimping length between the steel anchor and steel core is insufficient. As indicated in Figure 19, the simulated tensile load-displacement curves vary with respect to the different crimping conditions. When the crimping length between the steel anchor and steel core is $110 \mathrm{~mm}$ (standard crimping conditions) and $70 \mathrm{~mm}$, the load-displacement curves are 


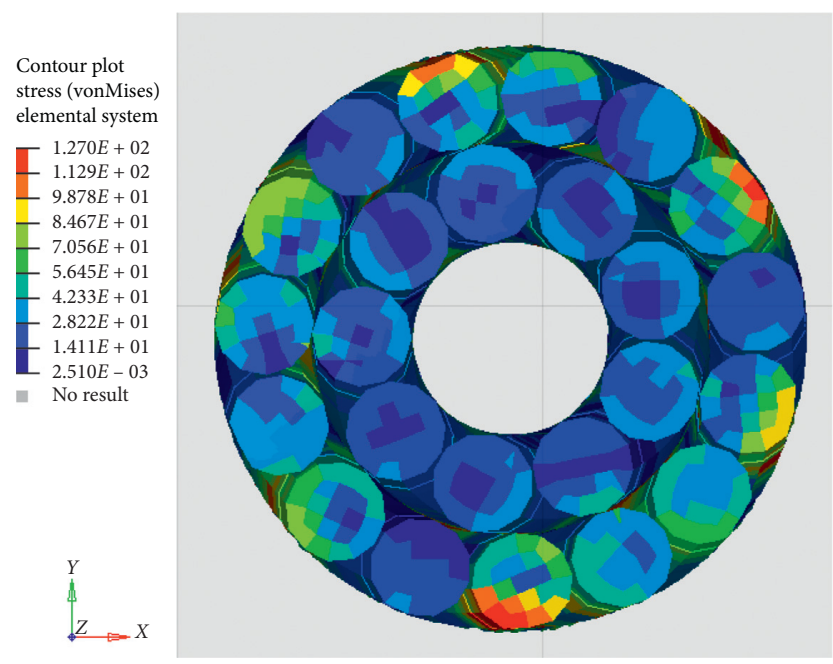

(a)

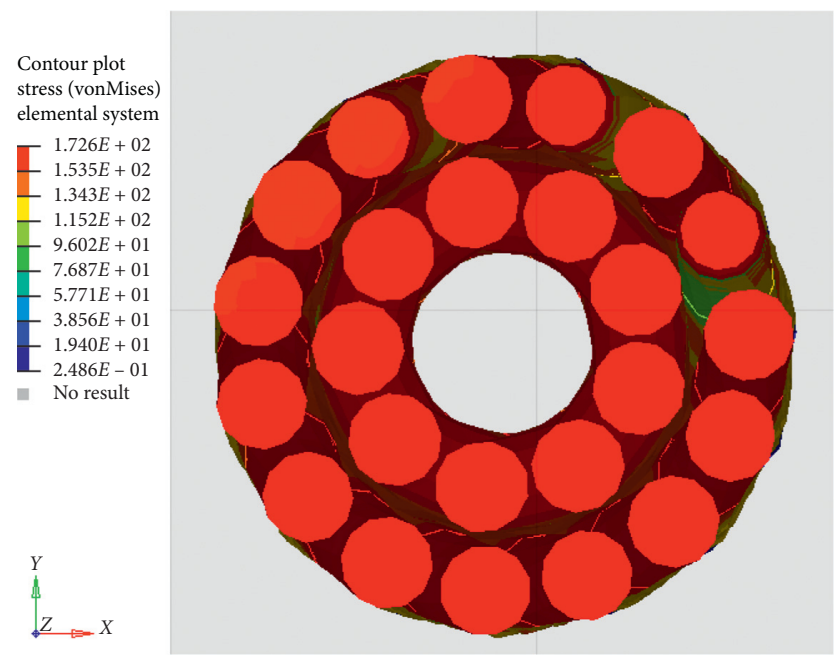

(c)

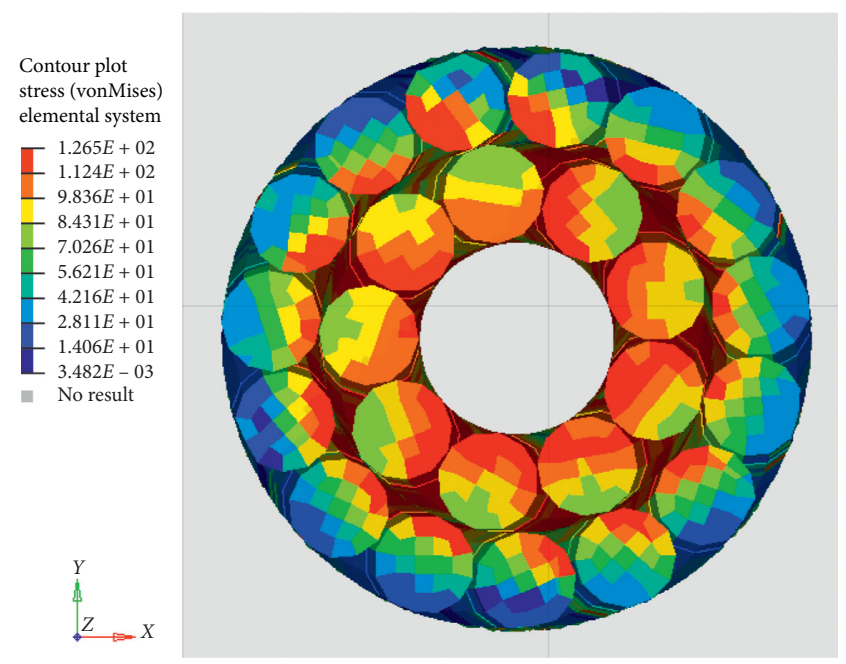

(b)

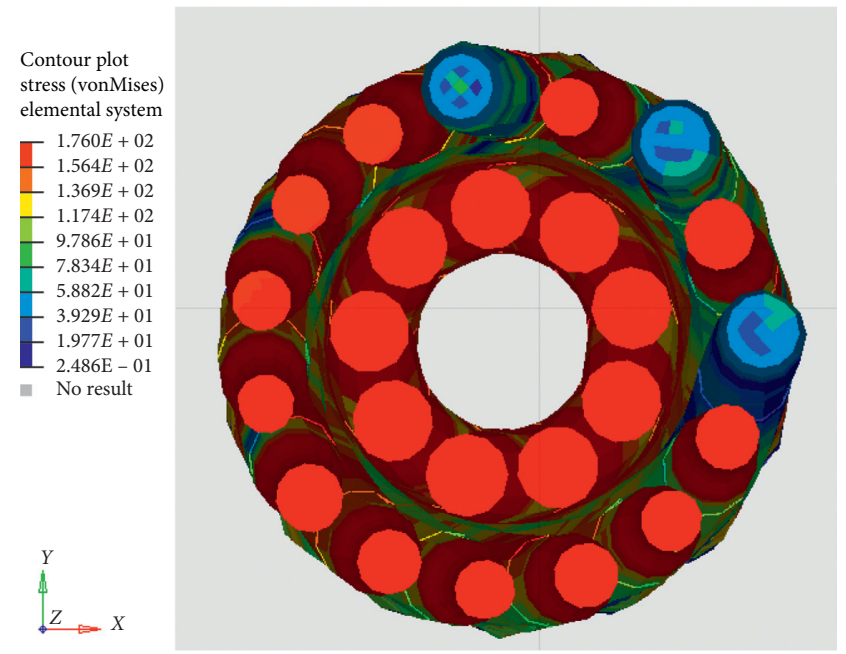

(d)

FIGURE 16: Stress nephograms of the cross section of the aluminum strand at the fracture location under different tensile loadings: (a) 25\% RTS; (b) 50\% RTS; (c) 95\% RTS; (d) ultimate load.

steep with a large peak value, which indicates that the strain clamp-conductor system has a large axial tensile stiffness and tensile strength. However, for crimping lengths of $50 \mathrm{~mm}$ and $60 \mathrm{~mm}$, the load-displacement curves are relatively gentle with the characteristics of large deformation, indicating that axial slip between the steel core and the steel anchor occurs during the stretching process.

Additionally, as demonstrated in Figure 19, when the crimping length is $50 \mathrm{~mm}, 60 \mathrm{~mm}$, and $70 \mathrm{~mm}$, the corresponding simulated breaking forces are $86.6875 \mathrm{kN}$, $91.0945 \mathrm{kN}$, and $93.6492 \mathrm{kN}$, respectively. The tensile breaking force increases with increasing crimping length, indicating that the crimping length is an important factor that influences the ultimate tensile load of the strain clampconductor system.

4.2. Analysis of the Stress Characteristics of the Aluminum Strands and the Steel Core during the Stretching Process.
To determine more about the stress characteristics of the strain clamp-conductor system under different crimping conditions, the following analysis was conducted.

4.2.1. Crimping Length between the Steel Anchor and Steel Core Is $50 \mathrm{~mm}$. When the crimping length is $50 \mathrm{~mm}$, the simulated breaking force is $86.6875 \mathrm{kN}$, which is lower than the designed grip strength of the clamp $(87.74 \mathrm{kN})$, indicating that the strain clamp could lose functionality before reaching the end of its scheduled design working life. Similar to Section 2.3, the stresses in the aluminum strand and steel core under typical tensile conditions are still extracted, and the results are shown in Figure 20.

When the tensile load does not exceed 50\% RTS, the stress in the middle portion of the aluminum strand is relatively small, whereas the stress at both ends is relatively large; the maximum stress in the aluminum strand is $125.9 \mathrm{MPa}$, and the overall stress is in an elastic state. Under the ultimate load, the 


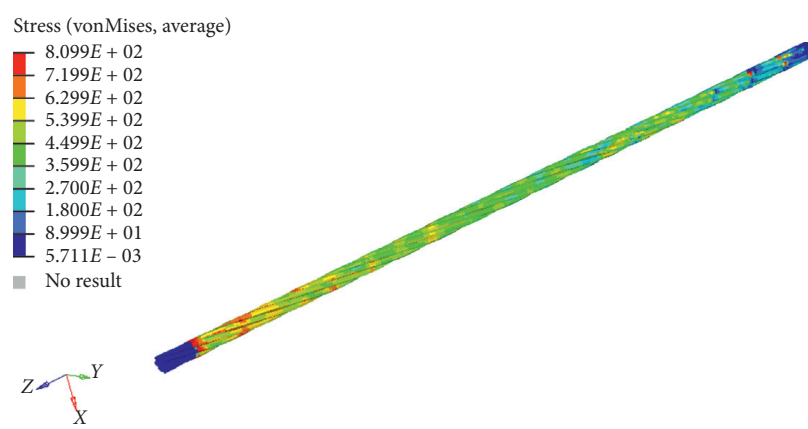

(a)

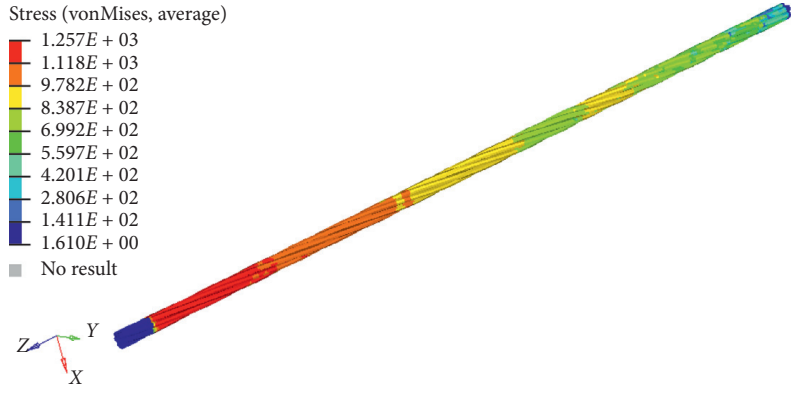

(c)

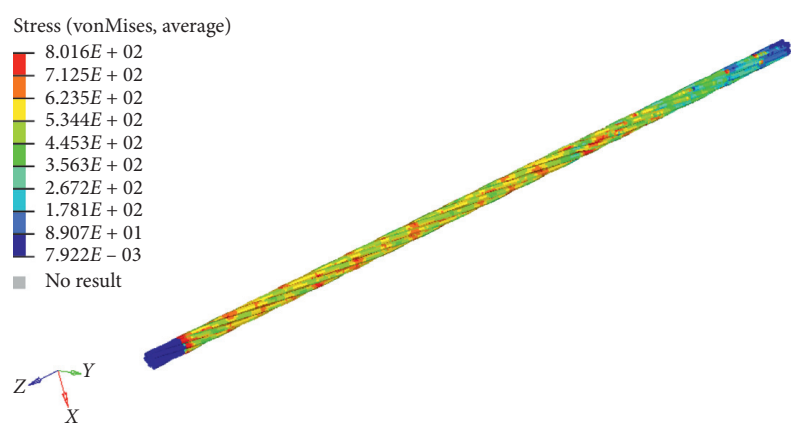

(b)

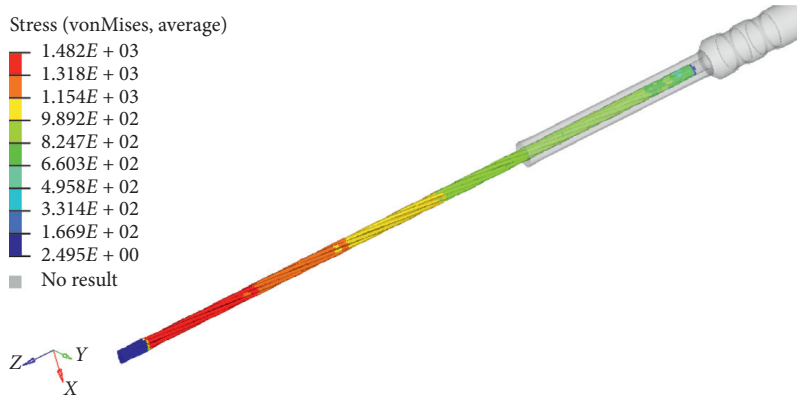

(d)

Figure 17: Stress nephograms of the steel core under different tensile loadings: (a) 25\% RTS; (b) 50\% RTS; (c) 95\% RTS; (d) ultimate load.

high-stress region in the aluminum strand changes from being symmetrically distributed at both ends to being located only near the outlet end of the aluminum pipe, wherein the maximum stress is $155 \mathrm{MPa}$; the stress in the other end away from the outlet is significantly smaller.

According to the stress in the steel core, the overall stress distribution in the steel core is extremely uneven, and the high stress is concentrated mainly in the steel core in the aluminum strand region. When the tensile load is $25 \%$ RTS, the maximum stress in the steel core is $781.9 \mathrm{MPa}$, which is much lower than its yield strength. When the tensile load increases to $50 \%$ RTS, the maximum stress reaches $1132 \mathrm{MPa}$, which is close to its yield strength. When the tensile force reaches the ultimate load, a long section of the steel core has been pulled from the steel anchor (Figure 20(c)). Although the steel core in the aluminum strand region still maintains a relatively large stress (the maximum stress is $946.3 \mathrm{MPa}$ ), due to the unloading effect caused by the steel core being pulled out of the steel anchor, it can be considered that the strain clamp has lost its tensile load-bearing capacity.

\subsubsection{Crimping Length between the Steel Anchor and Steel} Core Is $60 \mathrm{~mm}$. When the crimping length is $60 \mathrm{~mm}$, the tensile breaking force obtained from the simulation analysis is $91.0945 \mathrm{kN}$; the stress results for the aluminum strand and steel core under each typical tensile working condition are shown in Figure 21. As indicated in Figure 21, when the tensile load is $25 \%$ RTS or $50 \%$ RTS, the overall stress in the aluminum strand is relatively small and evenly distributed. When the tensile load increases to $95 \%$ RTS, the high stress in the aluminum strand is distributed mainly near the outlet of the aluminum pipe, whereas the stress is still very low in most other regions. When the ultimate load is reached, the aluminum strand near the outlet of the aluminum pipe exhibits a significant necking phenomenon, and some aluminum strands are completely broken.

During the stretching process, the stress in the central region of the steel core is relatively small, whereas the stress near the two ends is relatively large. The maximum stresses $\left.\begin{array}{lllll}\text { are } & 789.7 \mathrm{MPa} & (25 \% & \mathrm{RTS}\end{array}\right), \quad 907.4 \mathrm{MPa} \quad(50 \% \quad \mathrm{RTS})$, 1154.0 MPa (95\% RTS), and 1464.0 MPa (ultimate load). Therefore, during the entire stretching process, there is always a relatively large force between the steel core and the steel anchor, and the crimp can still maintain a certain bearing capacity when the ultimate load is reached. However, Figure 21(d) shows that the length of the crimped area between the steel anchor and the steel core has been significantly reduced, indicating that, under the ultimate load, although the steel core is not completely pulled out of the steel anchor, relative movement occurs between the steel core and the steel anchor. Due to the axial movement of the steel anchor before stretching, the actual overlap length after the steel core and the steel anchor are crimped is approximately $66.51 \mathrm{~mm}$. After stretching under the ultimate load, the actual overlap length between the two is $36.85 \mathrm{~mm}$, indicating that the steel core has been separated from the steel anchor by approximately $29.66 \mathrm{~mm}$.

4.2.3. Crimping Length between the Steel Anchor and Steel Core $I s 70 \mathrm{~mm}$. When the crimping length is $70 \mathrm{~mm}$, the breaking force obtained from the simulation analysis is 


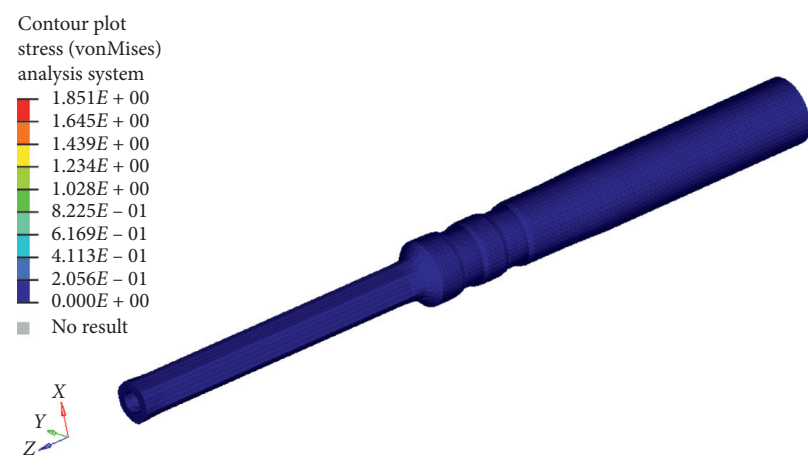

(a)

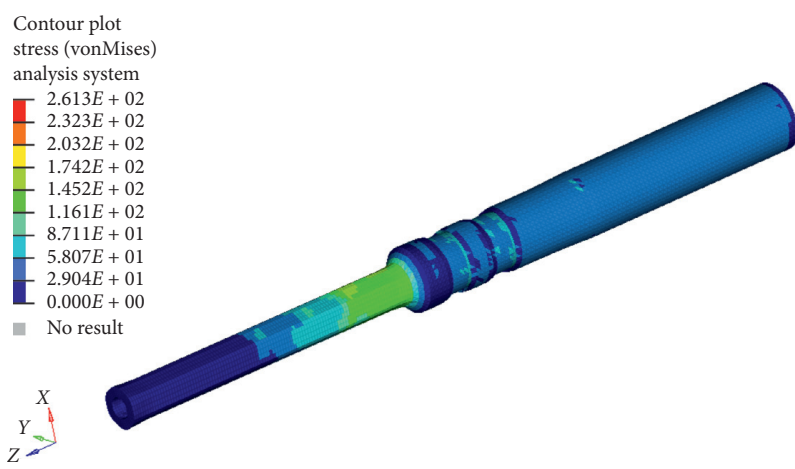

(c)

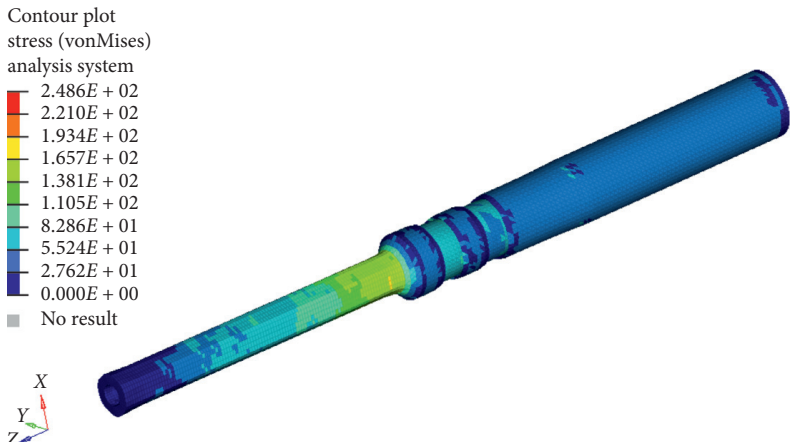

(b)

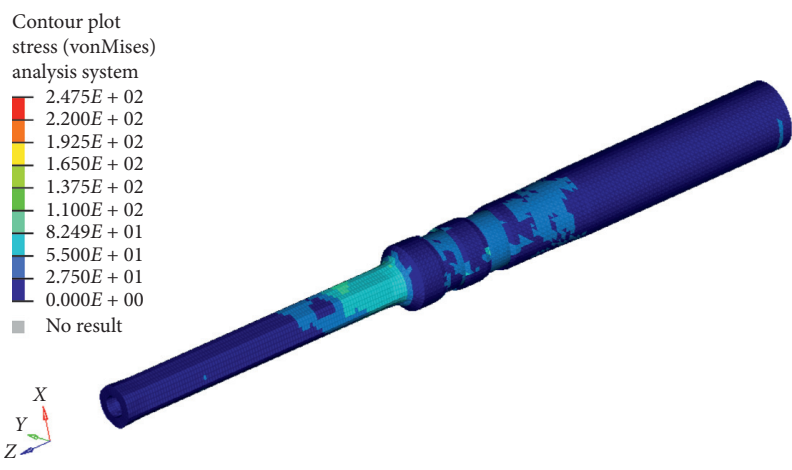

(d)

FiguRE 18: Stress nephograms of the steel anchor under different tensile loadings: (a) 25\% RTS; (b) 50\% RTS; (c) 95\% RTS; (d) ultimate load.

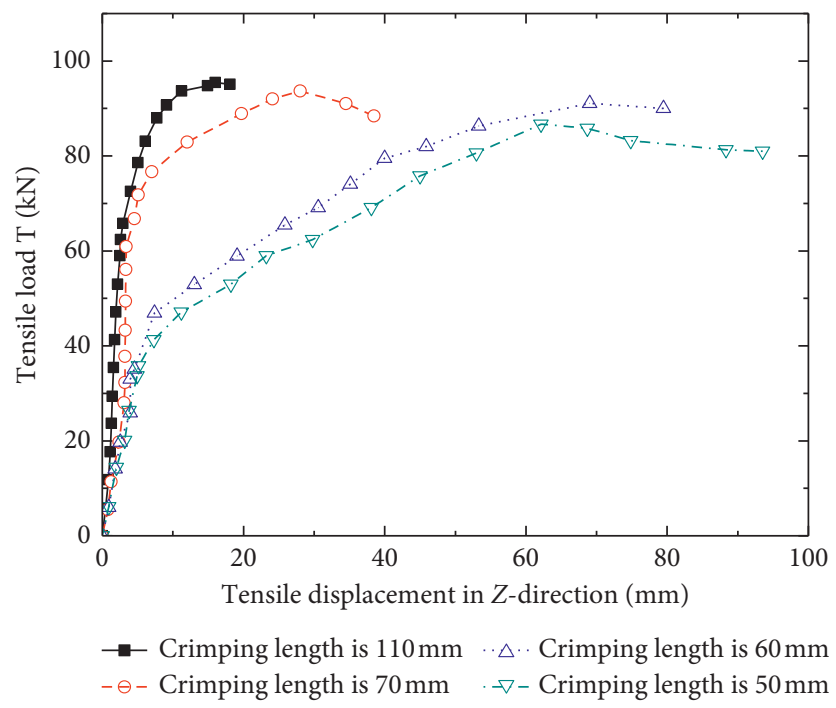

FIGURE 19: Comparison of the simulated tensile load-displacement curves of the strain clamp-conductor system under different crimping conditions.

$93.6492 \mathrm{kN}$. Figure 22 shows the stress results of the aluminum strand and the steel core under typical tensile conditions.

Figure 22 shows that when the load is lower than $50 \%$ RTS, the stress in the aluminum strand is relatively small and evenly distributed, and a large local stress exists only in the outlet region of the aluminum pipe. When the load continues to increase and reaches $95 \%$ RTS, the maximum stress in the aluminum strand near the outlet of the aluminum pipe is $169.2 \mathrm{MPa}$, which is close to its tensile strength. When the load reaches the ultimate load, multiple aluminum strands break in the outer layer near the outlet of the aluminum pipe. This failure condition is similar to that under the standard crimping situation. 


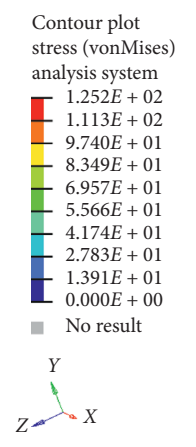

Contour plot

stress (vonMises) analysis system - $1.259 E+02$

- $9.795 E+01$

$-8.396 E+01$

$-6.997 E+01$

$-5.597 E+01$

$2799 E+0$

$-1.399 E+01$

$0.000 E+00$

- No result

$Y$
$Z-X$ stress (vonMises) analysis system

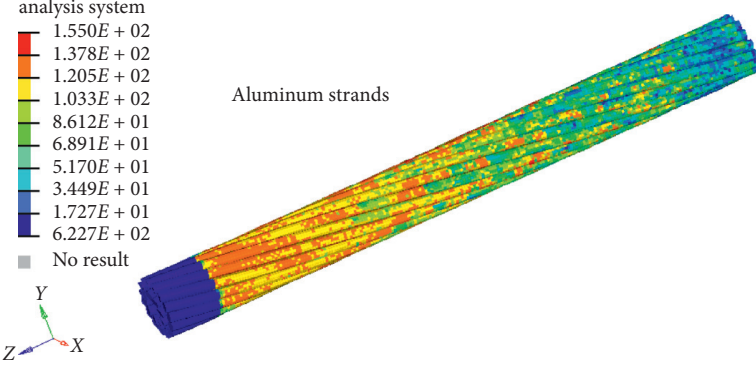

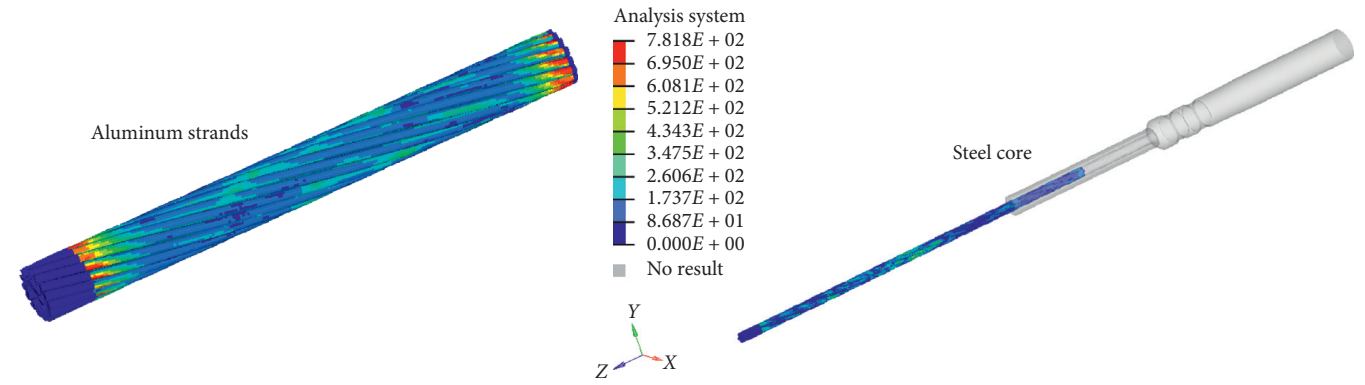

(a)

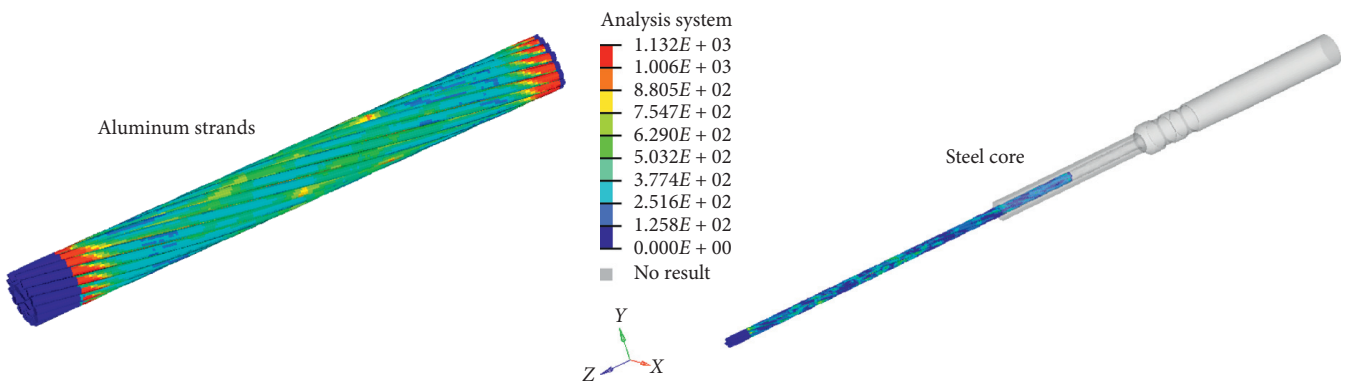

(b)

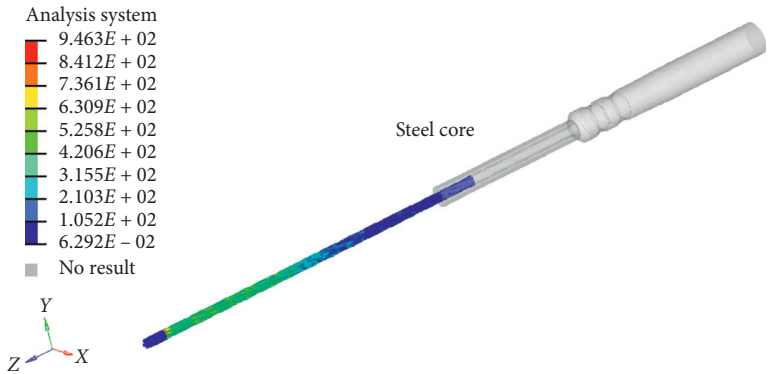

(c)

FIGURE 20: Stress in the aluminum strand and steel core under different tensile loadings: (a) 25\% RTS; (b) 50\% RTS; (c) ultimate load.

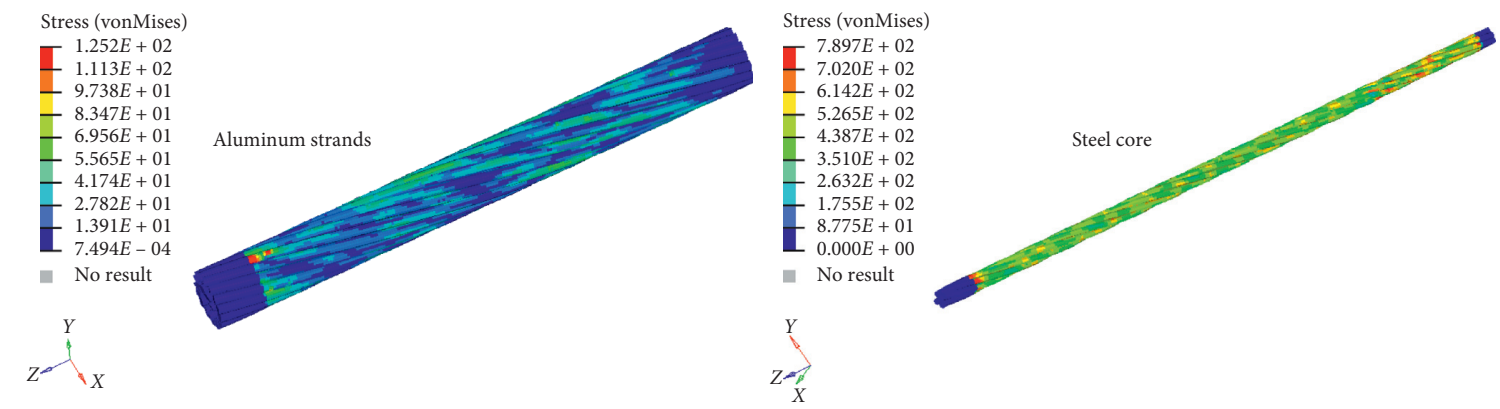

(a)

FIGURE 21: Continued. 


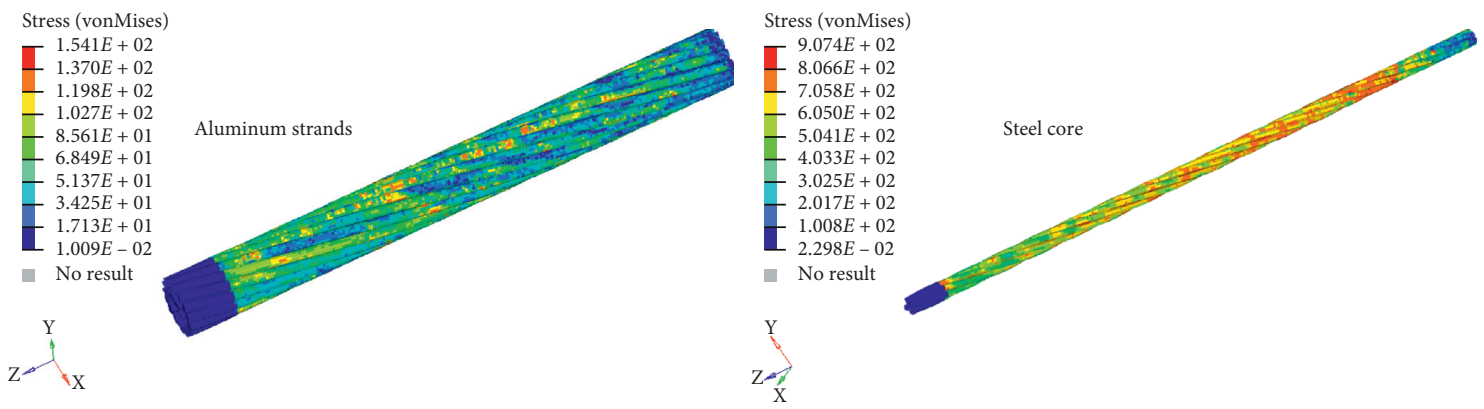

(b)

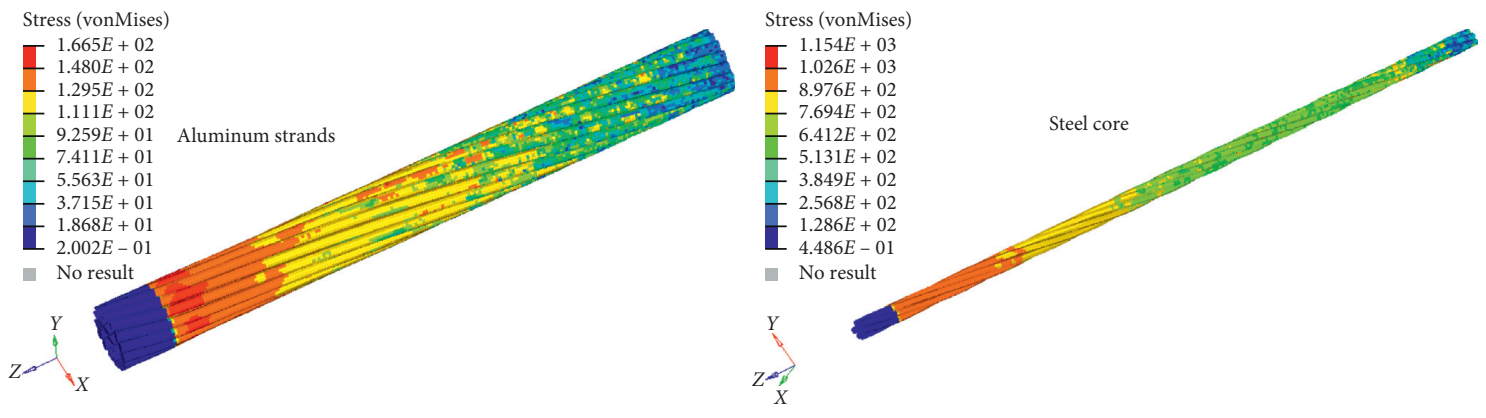

(c)
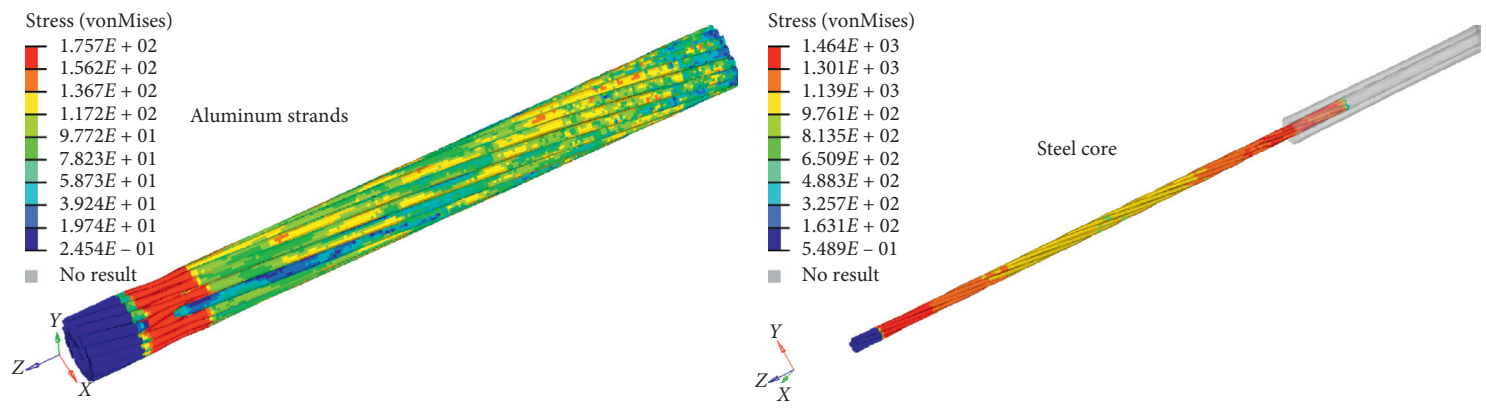

(d)

FIgURE 21: Stress in the aluminum strand and steel core under different tensile loadings: (a) 25\% RTS; (b) 50\% RTS; (c) 95\% RTS; (d) ultimate load.

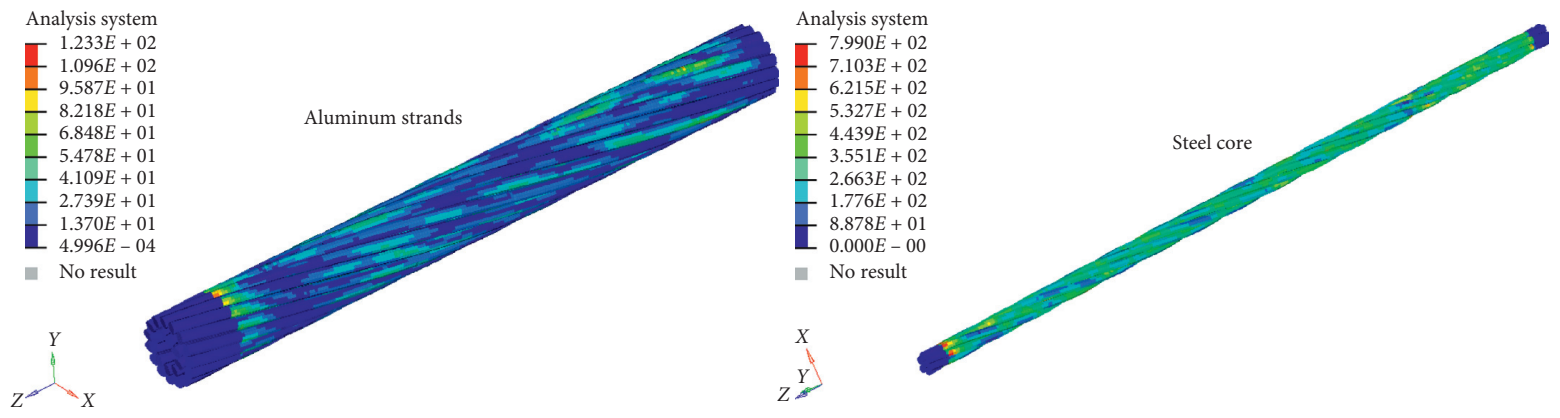

(a)

FIgURe 22: Continued. 


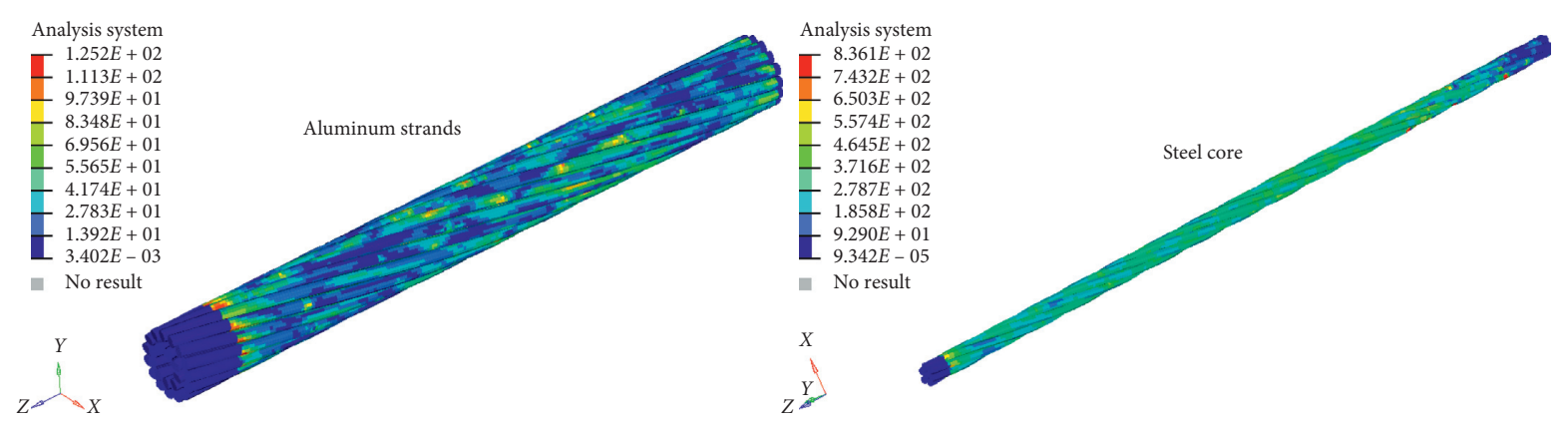

(b)

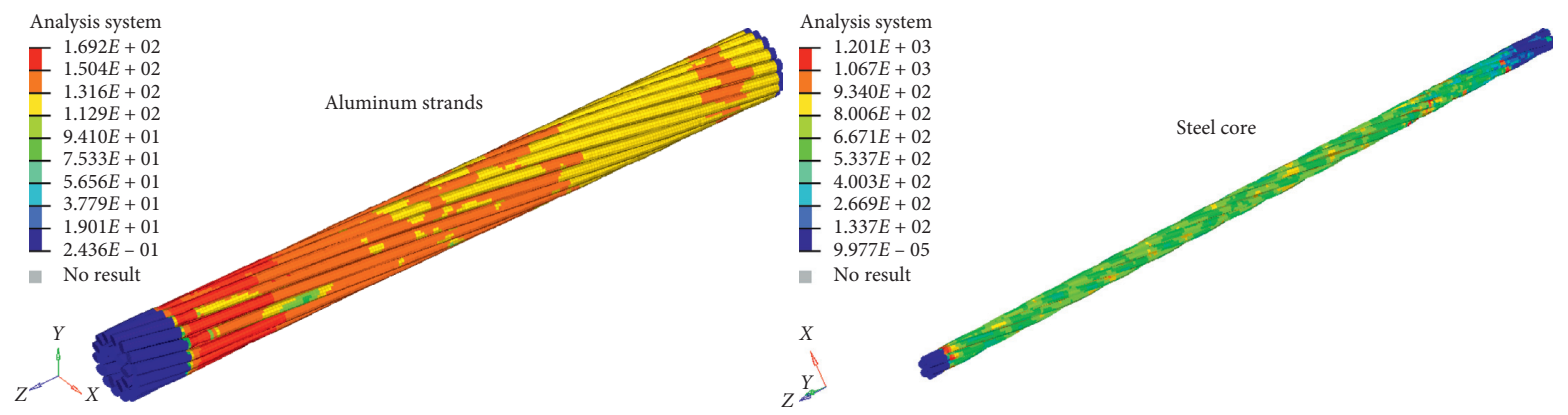

(c)

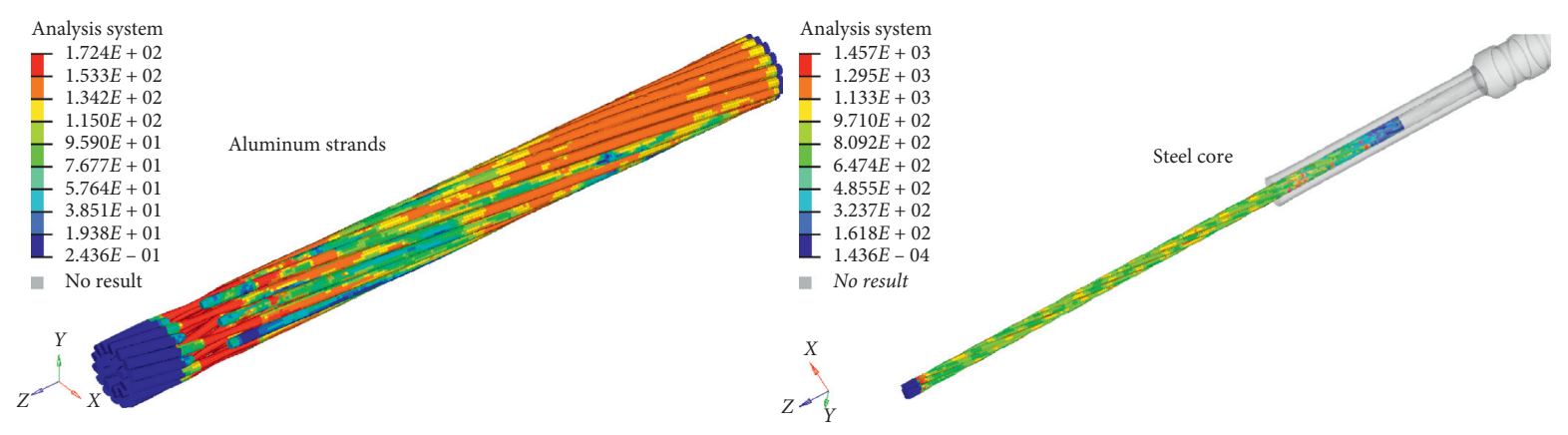

(d)

FIgURE 22: Stress in the aluminum strand and steel core under different tensile loadings: (a) 25\% RTS; (b) 50\% RTS; (c) 95\% RTS; (d) ultimate load.

For the steel core, during the entire stretching process, the stress in the central region of the steel core is relatively small and evenly distributed, and the high stress is concentrated mainly near the two ends. As the tensile load increases, the maximum stress in the steel core continues to increase. Under the ultimate load, there is still a relatively large stress in the crimped end between the steel core and the steel anchor (1457 MPa). The measurement results show that there are no changes in the crimping length between the steel core and the steel anchor, indicating that the two can still maintain good crimping under the ultimate load and that the steel core is not pulled out of the steel anchor. Thus, when the crimping length is $70 \mathrm{~mm}$, the failure mode of the strain clamp under a tensile load is aluminum strand breakage, which is similar to the failure mode under standard crimping conditions.

Based on the above analysis, when the crimping length is insufficient, the tensile load-bearing capacity of the strain clamp decreases as the crimping length decreases. Although the variation in the absolute value of the tensile breaking force is not large, the failure mode of the strain clamp gradually changes from the fracture of the aluminum strands due to necking to the steel core being pulled out of the steel anchor. For the NY-300/40 strain clamp analyzed in this paper, under nonstandard crimping conditions, the critical crimping length when this change in failure modes occurs is between $50 \mathrm{~mm}$ and $60 \mathrm{~mm}$.

\section{Conclusions}

In this paper, an NY-300/40 compression-type strain clamp is used to establish a $3 \mathrm{D}$ finite element model for the strain clamp-conductor system. LS-DYNA software is used to simulate and analyze the tensile load-bearing capacity and failure mode of the strain clamp-conductor system under standard crimping conditions and nonstandard crimping conditions (when the crimping length between the steel anchor and steel core is insufficient). The main conclusions are as follows: 
(1) It is feasible to use the finite element software LSDYNA to simulate and analyze the tensile mechanical behavior of a strain clamp-conductor system after crimping, and the simulation results have high accuracy.

(2) The grip strength of the strain clamp is provided mainly by the crimping between the steel anchor and the steel core. Under standard crimping conditions, the tensile load-bearing capacity of the strain clamp can meet the design requirements. Because the crimping length is sufficient, the failure mode is aluminum strand breakage instead of the steel core being pulled out of the steel anchor.

(3) When the crimping length between the steel anchor and the steel core is insufficient, as the crimping length decreases, the tensile load-bearing capacity of the strain clamp also gradually decreases. Although the variation in the absolute value of the breaking force is not significant, the failure mode of the clamp gradually changes from the fracture of the aluminum strands due to necking to the steel core being pulled out of the steel anchor.

(4) Taking an NY-300/40 strain clamp as an example, under nonstandard crimping conditions, the critical crimping length when this change in failure modes occurs is between $50 \mathrm{~mm}$ and $60 \mathrm{~mm}$.

\section{Data Availability}

The data used to support the findings of this study are included within the article.

\section{Conflicts of Interest}

The authors declare that there are no conflicts of interest regarding the publication of this paper.

\section{Acknowledgments}

This work was financially supported by the National Natural Science Foundation of China (grant no. 51578512), the China Scholarship Council, and the State Grid Corporation Headquarters Science and Technology Project of China (grant no. 52170218000G). The authors gratefully acknowledge the support.

\section{References}

[1] G. A. Pagani and M. Aiello, "The power grid as a complex network: a survey," Physica A: Statistical Mechanics and Its Applications, vol. 392, no. 11, pp. 2688-2700, 2013.

[2] M. Rosas-Casals and R. Solé, "Analysis of major failures in Europe's power grid," International Journal of Electrical Power \& Energy Systems, vol. 33, no. 3, pp. 805-808, 2011.

[3] OTA (Office of Technology Assessment), Physical Vulnerability of Electric System to Natural Disasters and Sabotage, OTA-E-453, U.S. Government Printing Office, Washington, DC, USA, 1990.

[4] G. Qian, Y. Cao, M. Niffenegger, Y. J. Chao, and W. Wu, "Comparison of constraint analyses with global and local approaches under uniaxial and biaxial loadings," European Journal of Mechanics-A/Solids, vol. 69, pp. 135-146, 2018.

[5] Z. Zhou, Z. Tong, G. Qian et al., "Irradiation effect on impact fracture behavior of A508-3 steel in ductile-to-brittle transition range," Engineering Failure Analysis, vol. 97, pp. 836843, 2019.

[6] D. Liao, S.-P. Zhu, and G. Qian, "Multiaxial fatigue analysis of notched components using combined critical plane and critical distance approach," International Journal of Mechanical Sciences, vol. 160, pp. 38-50, 2019.

[7] D. Meng, S. Yang, Y. Zhang, and S. P. Zhu, "Structural reliability analysis and uncertainties-based collaborative design and optimization of turbine blades using surrogate model," Fatigue \& Fracture of Engineering Materials \& Structures, vol. 42, no. 6, pp. 1219-1227, 2019.

[8] B. Li, H. Liu, T. Shen et al., "Irradiation-induced microstructure damage in He-irradiated $3 \mathrm{C}$-SiC at $1000^{\circ} \mathrm{C}$," Journal of the European Ceramic Society, vol. 40, no. 4, pp. 1014-1022, 2020.

[9] B. Li, H. Liu, L. Kang, T. Zhang, L. Xu, and A. Xiong, "Irradiation damage in xenon-irradiated $\alpha-\mathrm{Al}_{2} \mathrm{O}_{3}$ before and after annealing," Journal of the European Ceramic Society, vol. 39, no. 14, pp. 4307-4312, 2019.

[10] B. Li, Z. Wang, K. Wei et al., "Evaluation of helium effect on irradiation hardening in F82H, ODS, SIMP and T91 steels by nano-indentation method," Fusion Engineering and Design, vol. 142, pp. 6-12, 2019.

[11] B. Li, Y. Liu, H. Liu, L. Kang, and A. Xiong, "Transmission electron microscopy study of extended defects in high dose He-implanted GaN after annealing at $450^{\circ} \mathrm{C}$," Nuclear Instruments and Methods in Physics Research Section B: Beam Interactions with Materials and Atoms, vol. 454, pp. 45-49, 2019.

[12] C. Aj, M. A. Salam, Q. M. Rahman, F. Wen, S. P. Ang, and W. Voon, "Causes of transformer failures and diagnostic methods-a review," Renewable and Sustainable Energy Reviews, vol. 82, pp. 1442-1456, 2018.

[13] H. S. Ang, J. A. Pires, and R. Villaverde, "A model for the seismic reliability assessment of electric power transmission systems," Reliability Engineering \& System Safety, vol. 51, pp. 17-22, 1996.

[14] H. H. M. Hwang and J.-R. Huo, "Seismic fragility analysis of electric substation equipment and structures," Probabilistic Engineering Mechanics, vol. 13, no. 2, pp. 107-116, 1998.

[15] C. Klinger, M. Mehdianpour, D. Klingbeil, D. Bettge, R. Häcker, and W. Baer, "Failure analysis on collapsed towers of overhead electrical lines in the region Münsterland (Germany) 2005," Engineering Failure Analysis, vol. 18, no. 7, pp. 1873-1883, 2011.

[16] H. J. Dagher and Q. Lu, "System reliability analysis of transmission lines," Engineering Structures, vol. 15, no. 4, pp. 251-258, 1993.

[17] M. Zhang, G. Zhao, L. Wang, and J. Li, "Wind-induced coupling vibration effects of high-voltage transmission towerline systems," Shock and Vibration, vol. 2017, p. 34, 2017.

[18] T. Chanda, J. Zhou, and J. Duszczyk, "FEM analysis of aluminium extrusion through square and round dies," Materials \& Design, vol. 21, no. 4, pp. 323-335, 2000.

[19] M. Abbas, J.-L. Batoz, T. Courtin, and G. Dhatt, "Advanced numerical simulation of the crimping process of electric connectors," in Recent Advances in Integrated Design and Manufacturing in Mechanical Engineering, pp. 241-250, Springer, 2003Springer, Dordrecht, Netherlands, 4th International Conference. 
[20] M. Shirgaokar, G. Ngaile, T. Altan et al., "Hydraulic crimping: application to the assembly of tubular components," Journal of Materials Processing Technology, vol. 146, no. 1, pp. 44-51, 2004.

[21] C. Liu, H. D. Chen, K. J. Ouyang et al., "Analysis on the strain clamp fracture of ACCC," Electric Power, vol. 48, pp. 97-100, 2015.

[22] X. M. He, Z. H. Wang, F. Yun, W. Q. Chen, and G. F. Liu, "Analysis on reasons for fracture of $750 \mathrm{kV}$ wire and prevention measures," Hot Working Technology, vol. 47, pp. 257-262, 2018, in Chinese.

[23] M. Sun, C. Tan, C. Zhang, C. Yang, and H. Li, "Analysis of strain clamp failure on $500 \mathrm{kV}$ transmission line," Journal of Materials Science and Chemical Engineering, vol. 6, no. 4, pp. 47-56, 2018.

[24] L. Feng, M. Z. Li, L. Liu, and Z. Liu, "Study on completed fittings of $1520 \mathrm{~mm}^{2}$ large section conductors," in 3rd International Conference On Energy and Environment Research ICEER, pp. 284-290, Elsevier, Barcelona, Spain, September 2016, Energy Procedia.

[25] P. Rizzo and F. L. Di Scalea, "Load measurement and health monitoring in cable stays via guided wave magnetostrictive ultrasonics," Materials Evaluation, vol. 62, pp. 1057-1065, 2004.

[26] K. E. Cramer, D. F. Perey, and W. T. Yost, "A method for the verification of wire crimp compression using ultrasonic inspection," Research in Nondestructive Evaluation, vol. 21, no. 1, pp. 18-29, 2010.

[27] M. Finc, T. Kek, and J. Grum, "Quality control of crimped joint contacts with conductors through thermography," Insight-Non-destructive Testing and Condition Monitoring, vol. 57, no. 5, pp. 257-265, 2015.

[28] R. M. Wang, M. J. Zhan, and K. Ji, "Failure reason of tension clamp for high voltage electricity transmission," Materials for Mechanical Engineering, vol. 3, no. 41, pp. 112-116, 2017, in Chinese.

[29] A. K. Rajak and S. D. Kore, "Experimental investigation of aluminium-copper wire crimping with electromagnetic process: its advantages over conventional process," Journal of Manufacturing Processes, vol. 26, pp. 57-66, 2017.

[30] W. Wang, Q. Yuan, J. J. Gu, and N. L. Tai, “Application of $\mathrm{X}$-ray nondestructive flaw detection technology in transmission line's press fitting," Journal of Shanghai Jiaotong University, vol. 52, pp. 1189-1194, 2018, in Chinese.

[31] K. Kumar and J. Botsis, "Contact stresses in multilayered strands under tension and Torsion1," Journal of Applied Mechanics, vol. 68, no. 3, pp. 432-440, 2001.

[32] W. G. Jiang, M. K. Warby, and J. L. Henshall, "Statically indeterminate contacts in axially loaded wire strand," European Journal of Mechanics-A-Solids, vol. 27, no. 1, pp. 69-78, 2007.

[33] S. R. Ghoreishi, T. Messager, P. Cartraud, and P. Davies, "Validity and limitations of linear analytical models for steel wire strands under axial loading, using a 3D FE model," International Journal of Mechanical Sciences, vol. 49, no. 11, pp. 1251-1261, 2007.

[34] F. Lévesque, S. Goudreau, and L. Cloutier, "Elastic-plastic microcontact model for elliptical contact areas and its application to a treillis point in overhead electrical conductors," Journal of Tribology, vol. 133, no. 1, 2011.

[35] F. Lévesque, S. Goudreau, L. Cloutier, and A. Cardou, "Finite element model of the contact between a vibrating conductor and a suspension clamp," Tribology International, vol. 44, no. 9, pp. 1014-1023, 2011.
[36] R. B. Kalombo, J. A. Araújo, J. L. A. Ferreira, C. R. M. Da Silva, R. Alencar, and A. R. Capra, "Assessment of the fatigue failure of an all aluminium alloy cable (AAAC) for a $230 \mathrm{kV}$ transmission line in the center-west of Brazil," Engineering Failure Analysis, vol. 61, pp. 77-87, 2015.

[37] Altair Engineering, HYPERWORKS, HyperMesh 13.0 Manual, Altair Engineering Inc., Troy, MI, USA, 2014.

[38] J. O. Hallquist, LS-DYNA Keyword Manual, Vol. I, Livermore Software Technology Corporation (LSTC), Livemore, CA, USA, 2017.

[39] R. G. Whirley and B. E. Engelmann, "Automatic contact algorithm in DYNA3D for crashworthiness and impact problems," Nuclear Engineering and Design, vol. 150, no. 2-3, pp. 225-233, 1994.

[40] Y. Y. Lin and J. Wang, "Performance of the hybrid LS-DYNA on crash simulation with the multicore architecture," in Proceedings of the 7th European LS-DYNA Conference, Salzburg, Austria, May 2009.

[41] Electric Power Industry Standard of the People's Republic of China, Hydraulic Crimping Process Specification for Overhead Conductor and Ground Wire of Transmission and Transformation Project Construction, DL/T 5285-2018, Beijing, China, 2018.

[42] Electric Power Industry Standard of the People's Republic of China, Strain Clamp, DL/T 757-2009, Beijing, China, 2009.

[43] National Standard of the People's Republic of China, General Technical Requirements for Electric Power Fittings, GB/T 23142008, Beijing, China, 2008.

[44] National Standard of the People's Republic of China, Round Wire Concentric Lay Overhead Electrical Stranded Conductors, GB/T 1179-2008, Beijing, China, 2008.

[45] S. Huang, "Simulation and analysis of tensile mechanical properties of compressive strain clamp-conductor system," M.S. thesis, Zhengzhou University, Zhengzhou, China, 2019.

[46] National Standard of the People's Republic of China, Wrought Aluminium and Aluminium Alloy-Chemical Composition, GB/T 3190-2008, Beijing, China, 2008. 